Cita bibliográfica: Arnandis-i-Agramunt, R. (2018). Una revisión a la planificación de los recursos: sobre los enfoques de evaluación y los modelos de adaptación al uso turístico. Investigaciones Turísticas (15), pp. 168-197. http:// dx.doi.org/10.14198/INTURI2018.15.08

\title{
Una revisión a la planificación de los recursos: sobre los enfoques de evaluación y los modelos de adaptación al uso turístico*
}

\section{A resource planning review: evaluation approaches and adaptation to tourism purpose models}

Ruben Arnandis-i-Agramunt. Universidad de Valencia, España. ruben.arnandis@uv.es

\section{RESUMEN}

Mucho se ha hablado de la planificación del turismo. Solo cabe echar una mirada a la literatura académica para encontrar decenas de propuestas metodológicas que, desde inicios de los años 50 del siglo pasado, vienen exponiéndose. A pesar de esta vorágine creativa, todas ellas acaban, finalmente, enmarcándose en uno de los cinco enfoques identificados por Hall (2008). Sin embargo, al realizar ese mismo ejercicio para el caso de los recursos, considerados la base sobre la que asentar cualquier proceso de desarrollo turístico, los resultados sobre cómo planificarlos difieren considerablemente. Esta investigación, de carácter teórico, realiza una revisión bibliográfica de los trabajos académicos de las últimas décadas sobre recursos, con el objeto de identificar qué modelos existen hoy en día en torno a su planificación, sus similitudes y diferencias. Los resultados obtenidos reflejan una diversidad de modelos de planificación del turismo, así como los vinculados con la evaluación de la atractividad de los recursos, pero muy pocos asociados a su planificación específica para convertirlos en turísticos. Queda, todavía, un camino largo que recorrer sobre la aplicación de principios para adecuar al uso turístico la materia prima del turismo.

Palabras clave: enfoques de planificación, enfoques de evaluación, enfoques de adaptación, recurso turístico

\footnotetext{
* Este artículo se ha elaborado en el marco del proyecto "Sostenibilidad social, conectividad global y economía creativa como estrategias de desarrollo en el Área metropolitana de Valencia" (CSO2016-74888-C4-1-R), financiado por la Agencia Estatal de Investigación (AEI) y al Fondo Europeo de Desarrollo Regional (FEDER) dentro del Programa Estatal de Investigación, Desarrollo e Innovación Orientada a los Retos de la Sociedad, en el marco del Plan Estatal de Investigación Científica y Técnica y de Innovación 2013-2016, convocatoria de 2016.
} 


\section{ABSTRACT}

Much has been said about tourism planning. We only have to look into academic literature to trace dozens of methodological proposals that have been exposed since the early 1950s. Despite this creative maelstrom, all of them can be gathered within the framework of Hall (2008). However, when this exercise is applied to the case of resources, which form the basis upon which any tourism development process is built, the results about how to plan them differ considerably. In this theoretical investigation, which seeks to identify the models existing with respect to the planning, of resources and their similarities and differences, a bibliographic review of the academic studies published in recent decades has been conducted. The results reveal diversity in tourism planning models and those related to assessment of resource attractiveness. Nevertheless, very few studies are related to the specific planning in order to convert resources into tourist resources. Considerable ground has still to be covered in terms of adapting the raw material of tourism to tourism purposes.

Keywords: planning approaches, assessment approaches, adaptation approaches, tourism resource

\section{INTRODUCCIÓN}

Sin recursos no existiría el turismo. Esta afirmación, realizada por Gunn (1972) y respaldada, posteriormente, por autores como Camara y Morcate (2014), Ferrario (1979), Pigram (1983), Swarbrooke (2002) y Yale (2004), sostiene que sin materia prima difícilmente puede llevarse a cabo en el territorio un adecuado desarrollo de la actividad turística. Este argumento se fundamenta en que son los recursos los elementos básicos que atraen a las personas hasta un lugar concreto, siendo los servicios e infraestructuras aspectos complementarios, aunque también necesarios. Bien es cierto, no obstante, que los recursos pueden ser creados artificialmente para el turismo, pero deberá asumirse de partida que las ventajas competitivas serán cortas en el tiempo, por la facilidad de su reproducción en otros espacios.

Así pues, conscientes de la importancia de disponer de recursos diferenciados sobre los que asentar una estrategia de desarrollo turístico, los territorios deciden ponerse manos a la obra implementando, en primer lugar, un inventario capaz de determinar la cantidad y variedad de recursos para, posteriormente, iniciar el proceso de valoración (Viñals et al., 2011) y con él obtener el potencial turístico.

Y es justamente este proceso, el de valoración de los recursos para obtener su potencial, el que en mayor medida ha captado la atención de la academia, al menos, por lo que respecta a la cantidad de aportaciones metodológicas sobre cómo evaluar el atractivo de un recurso. Incluso pueden encontrarse propuestas ajustadas a la naturaleza del tipo de recurso (natural, cultural, inmaterial,...).

Ahora bien, obtener el potencial turístico es solo una parte del proceso de planificación de los recursos. Debe de existir, además, una adaptación de ese recurso al nuevo uso. Así lo expone la Teoría de la Renovación del Patrimonio Turístico, formulada por la Organización Mundial del Turismo (OMT) en 1979: la adaptación de los recursos al uso turístico resulta un aspecto necesario a la hora de garantizar que, tanto la experiencia 
del visitante como la preservación del recurso, se encuadran dentro de unos parámetros planificados.

Bajo esta premisa, esta investigación realiza una revisión de la literatura académica en lengua inglesa y española, publicada desde mitad del siglo XX hasta a la actualidad ${ }^{1}$, relacionada con la planificación, evaluación y adaptación de los recursos al turismo con el objeto de identificar, en primer lugar, qué papel ocupan los recursos en la planificación del turismo, en qué medida la propuesta de la Organización Mundial del Turismo ha sido integrada en los procesos de planificación de recursos y, finalmente, observar y exponer si la academia ha atendido de igual modo a los procesos de evaluación y de adaptación al uso turístico de los recursos territoriales.

Para tal finalidad, se ha considerado pertinente establecer una primera aproximación al concepto de planificación, en su sentido más general, con el objetivo de asentar sus bases. En segundo lugar, se expone la relación entre planificación y turismo, y cómo aquella ha ido adecuándose con paso del tiempo a las exigencias ambientales y sociales, ampliando el número de enfoques. Posteriormente, el artículo se centra en la planificación de los recursos, haciendo una breve introducción a su concepto, para pasar a presentar los modelos de evaluación y las propuestas de adaptación al uso turístico encontradas.

\section{DE LA PLANIFICACIÓN: CONCEPTUALIZACIÓN, PRINCIPIOS Y FINES BÁSICOS}

La planificación, entendida desde su concepción más genérica, adquiere importancia durante la modernización y eficacia de las administraciones públicas, iniciada con los trabajos de Fayol en 1916 y su análisis de las funciones y operaciones que debía realizar la administración de cualquier empresa. Posteriormente, fue el trabajo de Gulick (1937) el que trasladó las seis operaciones básicas de cualquier empresa a las funciones de la administración pública: planning (planificar), organizating (organizar), staffing (gestión del personal), directing (dirigir), co-ordinating (coordinar), reporting (informar) y budgeting (presupuestar).

Años después, y a pesar de no existir una doctrina sobre este tema, Waterson (1965) ya señalaba cierto consenso generalizado en que la planificación constaba de un proceso de racionalización a la hora de tomar decisiones, y que esta se ejecutaba a partir de una reflexión previa sobre las condiciones sociales, económicas y ecológicas posibles ante un hecho futuro.

Martner (1976) aporta a esta concepción seis principios, en un intento de definirla, a partir de los conceptos e ideas a ella asociados (cuadro 1). Para él planificar es un proceso en el que, tras la adopción de una actitud lo más racional posible, se ordenan los recursos escasos en función de los objetivos precisos.

1. Nota del autor: pueden observarse a lo largo del texto citas cuya fecha de publicación superan los 50 años de antigüedad. Este hecho se debe al interés en exponer la evolución de los métodos y de las ideas asociadas a la planificación de los recursos. 
Cuadro 1. Principios de la planificación según Martner (1976)

\begin{tabular}{|c|l|}
\hline Racionalidad & $\begin{array}{l}\text { Seleccionar alternativas de acción de forma inteligente, ponderando } \\
\text { sus ventajas e inconveniente y reduciéndolas a través del conocimiento } \\
\text { científico y del razonamiento sistemático a una decisión final coherente } \\
\text { que permita el aprovechamiento máximo de los recursos, teniendo } \\
\text { para ello en cuenta criterios económicos y administrativos. }\end{array}$ \\
\hline Previsión & $\begin{array}{l}\text { Puesto que la esencia de la planificación implica compromiso de futuro, } \\
\text { los planes, programas y proyectos se hacen en el presente con la vista } \\
\text { puesta en el mañana. }\end{array}$ \\
\hline Universalidad & $\begin{array}{l}\text { Toda planificación debería abarcar las fases del proceso económico, } \\
\text { social, administrativo y político, previendo las consecuencias de su } \\
\text { aplicación. Además, debería incluir no solo al Estado sino también a los } \\
\text { actores afectados por el proceso. }\end{array}$ \\
\hline Unidad & $\begin{array}{l}\text { Puesto que un objetivo de la planificación es impedir un uso inade- } \\
\text { cuado de los recursos, esta debe estar conectada con el resto de } \\
\text { planificaciones sectoriales a partir de un programa marco global }\end{array}$ \\
\hline Continuidad & $\begin{array}{l}\text { La planificación no tiene fin, por lo que los distintos planes se engarzan } \\
\text { para no malgastar los recursos ya empleados y anular la eficiencia del } \\
\text { proceso. }\end{array}$ \\
\hline Inherencia & $\begin{array}{l}\text { La planificación es inherente a cualquier organización, más al Estado, } \\
\text { por sus limitados recursos y la finalidad última de sus políticas. }\end{array}$ \\
\hline
\end{tabular}

Fuente: elaboración propia a partir de Martner (1976)

Así lo expresa mucho antes Muñoz (1963), al afirmar que planificar es definir objetivos, ordenar métodos y formas de organización, establecer medidas de tiempo, localizar espacialmente las actividades y otras especificaciones necesarias para encuadrar racionalmente la conducta de una persona o grupo (Muñoz, 1963, p.100). Subraya, sin embargo, que la planificación no es algo exclusivo del Estado (en Leno, 1992, p.292). Otros autores como Acerenza (1984) exponen que la planificación dirigida por la Administración Pública es un proceso racionalizador e indispensable que se lleva a cabo con el objetivo de coordinar y organizar los recursos disponibles para con ello alcanzar el bienestar y satisfacción de la ciudadanía y su progreso (en Ivars, 2003, p.98)

En esta misma línea se expresa Leno (1991), cuando indica que planificar es reducir el número posible de alternativas de acción a aquellas que mejor se ajustan a los fines propuestos y a los medios disponibles. Razquin (2002), que aborda la planificación desde la práctica y el derecho, lo hace como una función de intervención administrativa a través de la cual las administraciones públicas regulan una determinada área de actividad con un cierto carácter de globalidad y marcan las políticas públicas a desarrollar dentro de dichas áreas, a la vez que determina el marco jurídico de su desarrollo (Razquin, 2002, p.111)

Así pues, la planificación, como proceso de gestión de recursos para su uso racional, requiere de un marco normativo que estipule los límites a los que queda circunscrita y las consecuencias en caso de no ser aplicada. Murphy (1985) sugiere, además, que la planificación se relaciona con la anticipación y la regulación del cambio en un sistema para promover 
ordenadamente un desarrollo que incremente los beneficios sociales, económicos y medioambientales. Para tal finalidad, la planificación deviene una secuencia ordenada de operaciones, diseñada para liderar el logro de cada objetivo y el equilibrio entre todos ellos (Murphy, 1985, p.156).

Parece pues que la planificación, como ya la resumía Molina y Rodríguez (2005), se conforma a partir de un conjunto de acciones que tiene como finalidad que un fenómeno se comporte de una manera determinada, desde una realidad existente a otra deseada. No obstante, afirma que no existe un modelo único de planificación, pues, este dependerá, en cierta medida, de quien lo impulse. Si se revisan los modelos desarrollados por algunos sistemas políticos pueden observarse grandes diferencias, en relación al grado de implantación de las técnicas de planificación y de las actividades económicas a ellos relacionadas. En lo que sí parece haber consenso es en que más que un fin es un medio en sí misma, pues, en realidad forma parte de un proceso mucho mayor, el de gestión (Doswell, 1997, p.184), pensamiento ya propuesto inicialmente por Gulick (1937)

Cabe señalar que si bien la planificación también ha estado desde sus inicios relacionada con las políticas públicas, ya fuera esta derivada de la organización política de los Estados, la ideología dominante y el tipo de sistema económico presente, o la vinculada a los respectivos objetos de la planificación (económica, física, social, urbana, ambiental...)(Ivars, 2003), el proceso atribuido a los fines políticos-administrativos y a la toma de decisiones no es exclusivamente político. Es cierto que se inspira en él, pero también se combina con el conocimiento científico y técnico, como ya proponía Martner (1976) en sus seis principios anteriormente comentados. Sea como fuere, de lo que no cabe duda es de que la planificación no responde a un modelo concreto, pues dependerá en gran medida de los objetivos que persiga, de los recursos de los que parta, de las técnicas que se apliquen y del interés de quienes la realicen. Con todo, es difícil encontrar una actividad tanto económica como social o cultural que no haya sido objeto de una mínima planificación (Ivars, 2003), y la actividad turística, como era de esperar, no ha escapado a este hecho.

\section{DE LA PLANIFICACIÓN Y EL TURISMO: ENFOQUES DE REFERENCIA EN LA LITERATURA}

Es en el trabajo de Arrillaga (1962) donde se encuentra una de las primeras aportaciones sobre la planificación aplicada al turismo. Este autor la identifica con la labor previa e ineludible para la explotación óptima de las riquezas naturales con las que Dios ha regalado a una región y las obras artísticas, culturales e industriales que la laboriosidad, el tesón y la inteligencia de los habitantes han sabido crear en ella a través de los siglos (en Ivars, 2003, p.97)

Gunn (1979) también la identifica como la herramienta para el desarrollo de destinos, y cuyo foco de atención debe ser principalmente la generación de beneficios y empleo, así como asegurar la conservación de los recursos y la satisfacción de los visitantes. Boullón (2006) habla de ella como una actividad que permite una gestión racional de los elementos de la planta turística, y Molina (1986), en esta misma línea, de proceso racional y ordenado para alcanzar el crecimiento o el desarrollo turístico. Leno (1991) parece estar de acuerdo con Gunn (1979) cuando afirma que la no existencia de una planificación propiamente turística hace que 
sea la de carácter económico la que mejor se adecue a esta actividad. Sin embargo, la OMT (1999) aboga por un cambio en la visión que sobre la planificación del turismo se tiene hasta ese momento para ser interpretada con renovadas claves: como proceso de negociación entre los sectores implicados antes que como redacción de un documento de bases de actuación (Organización Mundial del Turismo, 1999, p.107)

Como señalará Andriotis (2000) en su tesis doctoral, la planificación es una actividad esencial hacia el logro de las metas del desarrollo turístico. Así lo manifiesta también Miralbell et al. (2010), en relación al número de leyes de turismo que, en el caso español, han sido aprobadas por las comunidades autónomas en las que parece contemplarse la planificación del turismo como una de las técnicas fundamentales para el desarrollo del turismo. Y por ello, la responsabilidad de la planificación del turismo también recae sobre los hombros del sector público, pues el sector privado está claramente orientado hacia la creación de productos turístico y no tanto hacia la conformación de áreas o destinos turísti$\cos$ (Gunn, 1997, p.12)

Todas estas aportaciones demuestran, inicialmente, tener un denominador común: aplicar la técnica planificadora para la gestión racional de los recursos en pro de un desarrollo turístico ordenado. Sin embargo, tampoco se plantea fácil el reto de establecer objetivos a la planificación del turismo, pues la naturaleza de tales objetivos dependerá de las preferencias locales, regionales o nacionales asentadas en los valores políticos, sociales, culturales, económicos y medioambientales, así como el estado de desarrollo en que se encuentren (Andriotis, 2000, p.63).

Así pues, la definición más acertada de planificación del turismo debería acotarse por los objetivos en los que se enmarca, en tanto en cuanto varían según los fines perseguidos y el enfoque (Ivars, 2003, p.100) (cuadro 2).

Sin embargo, puede observarse que, aunque la planificación del turismo no ha tenido hasta este momento unos fines consensuados, unificados o globales, su proyección parece no haber conocido más ley que la de la oferta y la demanda (Aramberri, 1986, p.4; Organización Mundial del Turismo, 1977, p.28). La razón de este hecho puede sustentarse en su efecto multiplicador: generador de empleo, aumento de la renta, diversificador de la economía, maximizador del beneficio (Dredge, 1999:772; Organización Mundial del Turismo, 1977, p.4; Valenzuela, 1986, p.54). De hecho, es su hegemonía económica la que ha anulado sus restantes vertientes (Vera et al., 2011, p.39). 
Cuadro 2. Enfoques para la planificación del turismo

\begin{tabular}{|c|c|c|c|c|}
\hline Enfoque & $\begin{array}{l}\text { Supuestos y actitudes } \\
\text { relacionadas }\end{array}$ & $\begin{array}{c}\text { Definición de los } \\
\text { problemas de } \\
\text { planificación turística }\end{array}$ & $\begin{array}{l}\text { Ejemplos de métodos } \\
\text { relacionados }\end{array}$ & $\begin{array}{l}\text { Ejemplos de modelos } \\
\text { relacionados }\end{array}$ \\
\hline Desarrollista & $\begin{array}{l}\text { - El turismo es bueno } \\
\text { por naturaleza } \\
\text { - Los recursos } \\
\text { naturales y } \\
\text { culturales deberían } \\
\text { ser explotados } \\
\text { - La industria como } \\
\text { experta } \\
\text { - El desarrollo } \\
\text { definido en } \\
\text { parámetros } \\
\text { empresariales }\end{array}$ & $\begin{array}{l}\text { - Cuántos visitantes } \\
\text { pueden se atraídos y } \\
\text { alojados } \\
\text { - Cómo hace frene a } \\
\text { los obstáculos } \\
\text { - Cómo convencer } \\
\text { a los residentes } \\
\text { del beneficio del } \\
\text { turismo }\end{array}$ & $\begin{array}{l}\text { - Promoción } \\
\text { - RRPP } \\
\text { - Publicidad } \\
\text { - Mercados } \\
\text { emergentes }\end{array}$ & $\begin{array}{l}\text { - Predicción de la } \\
\text { demanda }\end{array}$ \\
\hline Económico & $\begin{array}{l}\text { - El turismo como otra } \\
\text { industria } \\
\text { - El turismo para crear } \\
\text { empleo, obtener } \\
\text { beneficios de las } \\
\text { divisas y el comercio, } \\
\text { motivar el desarrollo } \\
\text { regional, vencer } \\
\text { las disparidades } \\
\text { económicas } \\
\text { - Los planificadores } \\
\text { como expertos } \\
\text { - Desarrollo definido } \\
\text { en términos } \\
\text { económicos }\end{array}$ & $\begin{array}{l}\text { - Puede el turismo } \\
\text { usarse como polo de } \\
\text { desarrollo } \\
\text { - Maximización de } \\
\text { los beneficios y } \\
\text { multiplicador del } \\
\text { empleo } \\
\text { - Influenciador en } \\
\text { las elecciones del } \\
\text { consumidor } \\
\text { - Provee valor } \\
\text { económico a las } \\
\text { externalidades } \\
\text { - Provee valor } \\
\text { económico a las } \\
\text { propuestas de } \\
\text { conservación }\end{array}$ & $\begin{array}{l}\text { - Análisis beneficio- } \\
\text { coste } \\
\text { - Análisis oferta- } \\
\text { demanda } \\
\text { - Conexión producto- } \\
\text { mercado } \\
\text { - Incentivos } \\
\text { al desarrollo } \\
\text { Segmentación de } \\
\text { mercados }\end{array}$ & $\begin{array}{l}\text { - Procesos de gestión } \\
\text { - Planes Maestros de } \\
\text { Turismo } \\
\text { - Motivación } \\
\text { - Impactos } \\
\text { económicos } \\
\text { - Multiplicadores } \\
\text { - Prenómicos } \\
\text { - Precios hedonistas }\end{array}$ \\
\hline $\begin{array}{l}\text { Físico / } \\
\text { espacial/ } \\
\text { territorial }\end{array}$ & $\begin{array}{l}\text { - El turismo como } \\
\text { usuario de recursos } \\
\text { - Base ecológica del } \\
\text { desarrollo } \\
\text { - El turismo como } \\
\text { fenómeno espacial y } \\
\text { regional } \\
\text { - Conservación del } \\
\text { medio ambiente } \\
\text { - Desarrollo definido } \\
\text { en términos } \\
\text { ambientales } \\
\text { - Preservación de la } \\
\text { diversidad genética } \\
\text { - El territorio como } \\
\text { expresión espacial } \\
\text { de los intereses } \\
\text { humanos }\end{array}$ & $\begin{array}{l}\text { - Capacidad de carga } \\
\text { física } \\
\text { - Manipulación de los } \\
\text { patrones y flujos de } \\
\text { visitantes } \\
\text { - Gestión de visitantes } \\
\text { - Mecanismos } \\
\text { inadecuados del } \\
\text { mercado } \\
\text { - Percepciones del } \\
\text { entorno natural } \\
\text { - Gestión de } \\
\text { naturaleza y parques } \\
\text { nacionales } \\
\text { - Identificación } \\
\text { de áreas } \\
\text { ambientalmente } \\
\text { sensibles }\end{array}$ & $\begin{array}{l}\text { - Evaluación del } \\
\text { impacto ambiental } \\
\text { - Estudios ecológicos } \\
\text { - Planificación } \\
\text { regional } \\
\text { - Estudios perceptivos } \\
\text { - Zonning }\end{array}$ & $\begin{array}{l}\text { - Patrones y procesos } \\
\text { espaciales } \\
\text { - Impactos físicos } \\
\text { - Morfología de los } \\
\text { resorts } \\
\text { - Límites del cambio } \\
\text { aceptable (LAC) } \\
\text { - Espectro de } \\
\text { oportunidades } \\
\text { recreacionales (ROS) } \\
\text { - Espectro de } \\
\text { oportunidades } \\
\text { turísticas (TOS) } \\
\text { - Ciclos de vida de los } \\
\text { destinos }\end{array}$ \\
\hline
\end{tabular}




\begin{tabular}{|c|c|c|c|c|}
\hline Comunitario & $\begin{array}{l}\text { - } \text { Necesidad del } \\
\text { - } \text { Búsquedrol local } \\
\text { desarrollo del } \\
\text { equilibrado } \\
\text { - Búsquedas } \\
\text { alternativas al } \\
\text { turismo masivo } \\
\text { - El planificador como } \\
\text { facilitador más que } \\
\text { experto } \\
\text { - Desarrollo definido } \\
\text { en términos } \\
\text { socioculturales }\end{array}$ & $\begin{array}{l}\text { - Cómo fomentar el } \\
\text { control comunitario } \\
\text { - Comprender las } \\
\text { actitudes locales } \\
\text { hacia el turismo } \\
\text { - Comprender los } \\
\text { impactos del } \\
\text { turismo en la } \\
\text { comunidad } \\
\text { - Impactos sociales }\end{array}$ & $\begin{array}{l}\text { - Concienciación y } \\
\text { educación } \\
\text { - Desarrollo } \\
\text { comunitario } \\
\text { - Encuestas sobre } \\
\text { actitudes } \\
\text { - Valoración del } \\
\text { impacto social }\end{array}$ & $\begin{array}{l}\text { - Visión ecológica de } \\
\text { la comunidad } \\
\text { - Capacidad de carga } \\
\text { social y perceptual } \\
\text { - Cambio actitudinal } \\
\text { - Multiplicador social }\end{array}$ \\
\hline Sostenible & $\begin{array}{l}\text { - Integración de los } \\
\text { valores sociales, } \\
\text { ambientales y } \\
\text { económicos } \\
\text { - Planificación del } \\
\text { turismo integrada } \\
\text { con otros procesos } \\
\text { de planificación } \\
\text { - Planificación } \\
\text { holística } \\
\text { - Preservación de los } \\
\text { procesos ecológicos } \\
\text { esenciales } \\
\text { - Protección de la } \\
\text { herencia humana y } \\
\text { la biodiversidad } \\
\text { - Equidad inter e } \\
\text { intrageneracional } \\
\text { - Logro de una } \\
\text { mejor equidad } \\
\text { de la justicia y las } \\
\text { oportunidades entre } \\
\text { países } \\
\text { - Planificación y } \\
\text { política como } \\
\text { argumento } \\
\text { - Planificación como } \\
\text { proceso } \\
\text { implanificación e } \\
\text { como las dos caras } \\
\text { de la misma moneda }\end{array}$ & $\begin{array}{l}\text { - Comprensión del } \\
\text { sistema turístico } \\
\text { - Ajustar las metas, } \\
\text { objetivos y } \\
\text { prioridades } \\
\text { - Lograr un } \\
\text { ajuste entre las } \\
\text { administraciones y } \\
\text { estas con el sector } \\
\text { privado } \\
\text { - Sistema integrados } \\
\text { y cooperativos de } \\
\text { control } \\
\text { - Comprender la } \\
\text { dimensión política } \\
\text { del turismo } \\
\text { - Planificar un turismo } \\
\text { que conecta las } \\
\text { necesidades locales } \\
\text { y el éxito comercial } \\
\text { en un mercado } \\
\text { competitivo } \\
\text { - Los cambios } \\
\text { suceden en un } \\
\text { ámbito multiescalar }\end{array}$ & $\begin{array}{l}\text { - Planificación } \\
\text { estratégica como } \\
\text { mejor aproximación } \\
\text { - Aumento de la } \\
\text { conciencia por parte } \\
\text { de los productores } \\
\text { - Aumento de la } \\
\text { conciencia por parte } \\
\text { de los consumidores } \\
\text { - Aumento de la } \\
\text { conciencia por parte } \\
\text { de los residentes } \\
\text { - Entrada de actores } \\
\text { en el proceso } \\
\text { - Análisis de las } \\
\text { políticas } \\
\text { - Investigación } \\
\text { evaluativa } \\
\text { - Economía política } \\
\text { - Análisis de las } \\
\text { aspiraciones } \\
\text { - Inspección de los } \\
\text { actores } \\
\text { - Análisis y auditoría } \\
\text { medioambiental } \\
\text { - Interpretación }\end{array}$ & $\begin{array}{l}\text { - Modelos de sistemas } \\
\text { - Modelos integrados } \\
\text { enfocados en los } \\
\text { lugares y los enlaces } \\
\text { y relaciones entre } \\
\text { ellos } \\
\text { - Recursos como } \\
\text { elementos } \\
\text { culturalmente } \\
\text { constituidos } \\
\text { - Percepción del } \\
\text { medioambiente } \\
\text { - Asunto ecológico } \\
\text { - Organizaciones del } \\
\text { conocimiento } \\
\text { - Gobernanza }\end{array}$ \\
\hline
\end{tabular}




\begin{tabular}{|c|c|c|c|}
\hline Estratégico & $\begin{array}{l}\text { - El turismo funciona } \\
\text { bajo influencias } \\
\text { constantes } \\
\text { - Enfoque } \\
\text { prospectivo, } \\
\text { dinámico y creativo } \\
\text { de la planificación } \\
\text { - Definición de la } \\
\text { política turística } \\
\text { como un todo } \\
\text { interrelacionado } \\
\text { - La planificación es } \\
\text { capaz de adaptarse } \\
\text { ante contextos } \\
\text { cambiantes e } \\
\text { inciertos }\end{array}$ & $\begin{array}{l}\text { - Conciliar la oferta de } \\
\text { los destinos con las } \\
\text { necesidades de la } \\
\text { demanda } \\
\text { - Comprender el } \\
\text { entorno en el } \\
\text { que el turismo se } \\
\text { desenvuelve } \\
\text { - Establecer } \\
\text { estrategias y planes } \\
\text { - Adaptar los medios } \\
\text { existentes a los } \\
\text { objetivos trazados } \\
\text { - Solucionar las } \\
\text { debilidades del } \\
\text { destino } \\
\text { - Definir posibles } \\
\text { escenarios futuros }\end{array}$ & $\begin{array}{l}\text { - Estudios de oferta- } \\
\text { demanda } \\
\text { - Análisis de la } \\
\text { competencia y del } \\
\text { mercado } \\
\text { - Potenciación de la } \\
\text { competitividad de } \\
\text { los destinos } \\
\text { - Análisis DAFO }\end{array}$ \\
\hline
\end{tabular}

Fuente: traducción y elaboración propia a partir de Getz (1987), Hall y Lew (1998), Hall (2000), Hall y Page (2010), Osorio (2006), Phillips y Moutinho (2014), Ricaurte (2009) y Simancas (2016).

Y esta situación no es nueva de ahora. La Unión Internacional de Organismo Oficiales de Turismo (1971b), tras comprobar la amplia diversidad de métodos de planificación del turismo que los países venían desarrollando hasta finales de la década de 1960, advirtió del necesario posicionamiento de la planificación a niveles más generales, para que fuera capaz de tener en cuenta la evolución en curso y previsible de los fenómenos sociales y las características de las corrientes turísticas. La idea no era otra que asegurar que estas planificaciones actuasen como un instrumento para prever y evaluar todas las interacciones entre las actividades económicas y sociales, que pudieran derivar del desarrollo del fenómeno turístico (Unión Internacional de Organismos Oficiales de Turismo, 1971b:12)

A pesar de estas advertencias, muy poca fue la atención que se prestó a los efectos socioculturales y ambientales de los territorios de acogida y que, con el paso del tiempo, sobrepasaron a los beneficios esperados (Andriotis, 2000:61). Así pues, la experiencia demuestra que aquellos espacios turísticos que han sido planificados inadecuadamente, o sencillamente no lo han sido, ya sea por la presión de la demanda en la configuración del destino o por los impulsos de los sectores involucrados, sufren a largo plazo complicaciones de tipo ambiental y social (Inskeep, 1991, p.15; Mason, 2003, p.25; Organización Mundial del Turismo, 1977, p.4).

El turismo mal entendido va en detrimento de los residentes (Burns, 2004; Reid et al., 2004; Stylidis et al., 2014; Wang y Xu, 2015), afecta a la satisfacción de los propios visitantes, y acaba originando una pérdida de la competitividad y un decrecimiento de los beneficios que el turismo reporta (Organización Mundial del Turismo, 1994). Los impactos sociales fueron ampliamente estudiados por sociólogos y antropólogos en la década de los 70 y 80 en Estados Unidos (Andereck y Vogt, 2000) porque la opinión de la sociedad receptora hacia el turismo se reconoce como un factor que determina la valoración de la experiencia turística (Mantecón, 2016). De hecho, hoy en día este tema ha vuelto a la arena, bajo el nombre de 
turismofobia (Huete y Mantecón, 2018), que asociado a la masificación de muchos espacios urbanos, reconfiguran la percepción que el residente tiene sobre el visitante, y generando en muchas ocasiones un malestar difícil de reconducir (Almeida et al., 2015), pero que requiere una urgente solución.

Es en este instante, cuando debería admitirse que el mercado no es un adecuado mecanismo por sí mismo ni para proteger los intereses de todos los actores ni para corregir los desequilibrios territoriales (Anton y González, 2005, p.17), no pudiéndose permitir que el crecimiento de la industria turística siga las fuerzas de la demanda por sí sola (Pearce, 1988, p.99). La intervención del Estado en esta materia parece entonces clave para aplicar la planificación al turismo, pues sin una implicación pública esta no tendría una dirección clara y podría verse gravemente comprometida a largo plazo (Lickorish y Bodlender, 1991).

Así que si existe algún ámbito donde la planificación sea un requisito sine qua non ese es el turismo. Las razones son: a) afecta de lleno a la gestión de los recursos disponibles, muchas veces de carácter público, escasos y sujetos a demandas que pueden entrar en conflicto, b) constituye una actividad cuyas aportaciones a la renta y al empleo favorecen un mayor bienestar social, c) genera impactos ambientales y socioculturales que afectan de manera negativa a la calidad de vida de la población local, d) por la diversidad de actores vinculados directa o indirectamente con sus efectos.

La planificación se vislumbra entonces como la única salvación ante tales males, introduciendo criterios de racionalidad y sostenibilidad ante la transformación del espacio, la sociedad y la economía que produce el turismo. No obstante, las dificultades y los costes en que deberá incurrirse cuando no se ha planificado, o se ha hecho incorrectamente, se manifestarán como muy superiores, cuando no inalcanzables (Ivars, 2003, p.98; Organización Mundial del Turismo, 1994, p.3)

\section{DE LA PLANIFICACIÓN Y LOS RECURSOS: SU RELEVANCIA EN LOS MODELOS DE PLANIFICACIÓN DEL TURISMO.}

\subsection{Del concepto de recurso}

La Real Academia Española de la Lengua define recurso, en su segunda entrada, como medio de cualquier clase que, en caso de necesidad, sirve para conseguir lo que se pretende. Aunque se recurra a su plural, su significado no varía notablemente. Son recursos el conjunto de elementos disponibles para resolver una necesidad o llevar a cabo una empresa. Ambas definiciones, en singular y plural, comparten, pues, un elemento en común: todo recurso tiene por objetivo cubrir una necesidad.

Al observar etimológicamente su raíz, la palabra recurso, que significa fuente, lleva además asociado el prefijo re (en latín "otra vez"), cuyo significado podría sugerir una dependencia del tiempo. Desde ese punto de vista, el concepto de recurso adquiere una visión netamente funcional e inseparable de los deseos y de las capacidades del ser humano, por lo que es un concepto que pertenece legítimamente a la ciencia social (Zimmermann y Robles, 1957, p.21). En esta misma línea, el economista estadounidense Mitchel (1941) comenta en 
su obra que el mayor de los recursos del ser humano, sin punto de comparación, es el conocimiento. Y parece serlo porque es el creador de los demás recursos (Bowman, 1934).

En la figura 1 puede observarse lo que para Zimmermann y Robles es una relación sencilla existente entre el ser humano primitivo y la naturaleza. En cambio, a medida que va desarrollándose y tomando conciencia de sí mismo y de su entorno, las relaciones se vuelven más complejas. La idea de representar a la cultura en forma de punta de lanza, la cual se introduce de manera abrupta dentro de la naturaleza, convirtiendo progresivamente los elementos neutros en recursos (con las consiguientes resistencias que puede encontrar), es un claro ejemplo de cómo el ser humano selecciona los elementos de la naturaleza en la medida en que les encuentra significado para satisfacer sus necesidades.

Figura 1. Relación entre ser humano, cultura y naturaleza

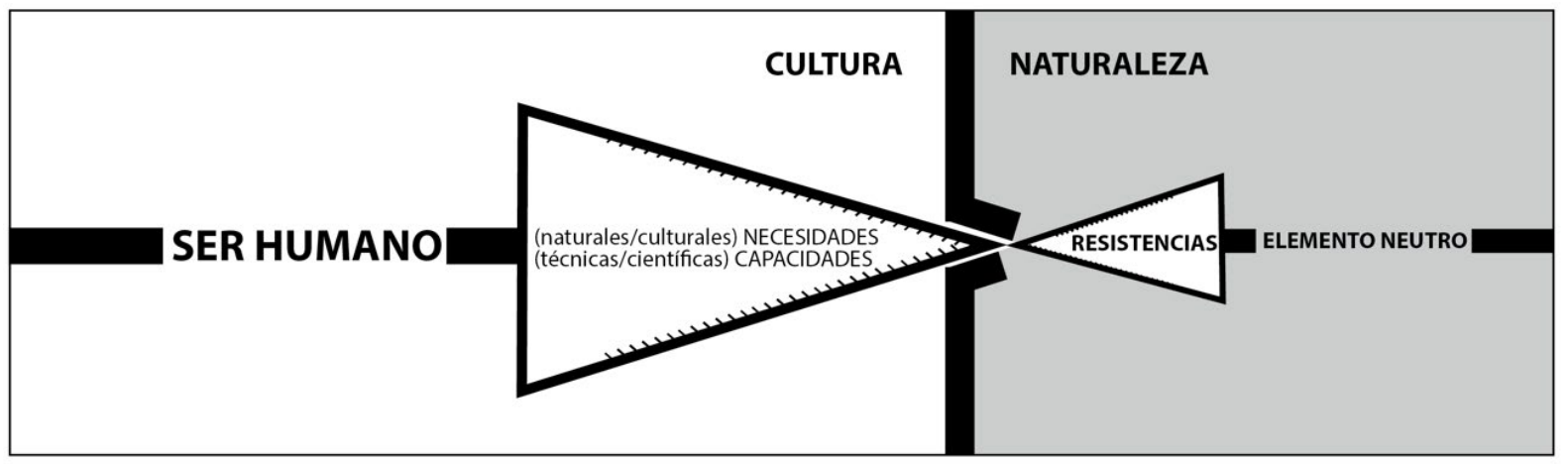

Fuente: elaboración propia a partir de Zimmermann y Robles (1957)

Así pues, las personas, a través de sus necesidades individuales y finalidades sociales, confieren sentido y uso a los recursos. Es decir, en verdad, los atributos que posee un recurso no existen hasta que el ser humano percibe su existencia [por necesidad], reconoce su utilidad $y$, además, posee los medios adecuados para explotarlo.

Esto significa, ni más ni menos, que en el momento en que las dos subesferas que conforman el sistema cultura-naturaleza entran en contacto, la de lo social atribuye a determinados elementos de lo natural un valor, el cual vendrá definido por su capacidad de satisfacer necesidades, ya sean de carácter físico-biológico o cultural-estético (Barrado, 2011)

No obstante, cabe matizar algunas consideraciones:

1. Esta valoración del elemento neutro debe ser entendida, además, dentro de un marco más amplio, pues, será también a partir del conocimiento científico y de la tecnología de la que se disponga cuando las necesidades podrán ser satisfechas por ese recurso.

2. Ninguna de esas valoraciones será percibida objetivamente, pues estarán siempre condicionadas por las nociones ideológicas y socioeconómicas.

Se está, pues, ante un concepto, el de recurso, que depende inicialmente de la valoración cultural que de él se haga, por lo que aun cuando se refiera a elementos que pueden venir dados por la naturaleza del recurso, traspasa con creces el estricto ámbito del análisis del medio físico, entrando de lleno en el terreno de lo cultural y, por ende, de marcado carácter 
subjetivo. Así es como Barrado (2011) se expresa añadiendo, además, que entender la concepción de recurso implica centrar la atención en la relación sociedad-medio y en cómo este es puesto al servicio de la sociedad a partir de sus sistemas culturales y en función de sus necesidades e intereses (Barrado, 2011, p.41).

\subsection{Del recurso como la base para la planificación del turismo}

De los modelos de planificación del turismo (Lawson y Baud-Bovy, 1977, pp.138,139,142), asociados a cada uno de los enfoques presentados anteriormente, se desprende que el proceso de evaluación de los recursos, para identificar cuan atractivos pueden ser para la demanda, se encuentra explícitamente en la primera fase de la planificación (tanto para el modelo desarrollista, como económico y físico-espacial). Para el caso del modelo comunitario (Burns, 1999, p.32), se habla inicialmente de "potencialidad turística" aunque no se especifica con claridad qué variables cabe considerar para tal fin. Sin embargo, ni el sostenible ni el estratégico exponen con claridad en qué lugar se ubica la evaluación de los recursos por lo que, quizá, se está ante enfoques para la planificación pero sin modelos concretos asociados (Hall, 2008; López Palomeque, 2007; Organización Mundial del Turismo, 1999; United Nations World Tourism Organization, 2005; Valls, 1996).

Cuadro 3. Los recursos en la planificación del turismo

\begin{tabular}{|c|c|c|c|}
\hline Autores & Año & $\begin{array}{c}\text { Fases propuestas en el } \\
\text { proceso de planificación del } \\
\text { turismo }\end{array}$ & \begin{tabular}{|c} 
Fase en la que se \\
encuentra la evaluación de \\
los recursos \\
\end{tabular} \\
\hline Lawson y Baud-Bovy & 1977 & 4 & 1 \\
\hline Gunn & 1979 & 5 & 2 \\
\hline Kaiser y Helber & 1983 & 10 & 4 \\
\hline Mill y Morrison & 1985 & 5 & 2 \\
\hline Pearce & 1988 & 5 & 1 \\
\hline Bote & 1990 & 4 & 1 \\
\hline Inskeep & 1991 & 8 & 3 \\
\hline OMT & 1994 & 7 & 3 \\
\hline Gunn & 1994 & 5 & 2 \\
\hline Gunn & 1997 & 7 & 4 \\
\hline Vera et al. & 1997 & 3 & 1 \\
\hline Lawson y Baud-Bovy & 1998 & 4 & 1 \\
\hline Godfrey \& Clarke & 2000 & 8 & 2 \\
\hline Gunn & 2002 & 5 & 4 \\
\hline Zamorano & 2002 & 3 & 1 \\
\hline Ivars & 2003 & 8 & 2 \\
\hline López & 2006 & 7 & 3 \\
\hline Otero & 2008 & 3 & 1 \\
\hline Mill y Morrison & 2009 & 7 & 2 \\
\hline Vera et al. & 2011 & 3 & 1 \\
\hline
\end{tabular}

Elaboración propia 
Mientras existen modelos de planificación del turismo que incorporan en algún momento del proceso una fase específica sobre la evaluación de los recursos, estos coexisten con otros cuya fase no queda tan explícita. Tal es así en los trabajos de Boullón (1978), Hernández Díaz (1982), Molina (1986), Reid et al. (2004), Molina y Rodríguez (2005), Cooper et al. (2007) o Hall (2008).

Sea como fuere, esta importancia de los recursos para la actividad turística puede advertirse a partir de su ubicación dentro del proceso de planificación del turismo (cuadro 3). Es en las fases iniciales de análisis y diagnóstico donde se observa una mayor presencia (Barrado y Ávila, 2010; Calderón, 2005; Callizo y Lacosta, 1999; Cebrián y García, 2010; Nakayama, 1993). De ahí que autores como Antón y González (2005), Calderón (2005), Conti y Cravero (2010), Ferrario (1979), Gunn (1979; 1997), Ivars (2003), Leno (1990), López (1998; 2014), Lundberg (1985), Pearce (1989), Sancho y Buhalis (1998), Sessa (1975) y Solsona (1999), la identificaran en sus trabajos como la materia prima del turismo.

Así pues, los recursos, ya sean artificiales o naturales, son considerados los componentes esenciales del producto turístico de cualquier territorio (Camara y Morcate, 2014; de Grandpre, 2007; Fyall et al., 2001; Gunn, 1994; Hu y Wall, 2005; Lundberg, 1985; Middleton, 2001; Pulido et al., 2013; Swarbrooke, 2002; Vera et al., 2011; Watson y MacCracken, 2002), son la base que motiva el desplazamiento de los visitantes y el factor de localización de los servicios (Goeldner y Ritchie, 2006; Herrera et al., 2012; Varisco et al., 2014), son el foco más importante para la actividad turística (Richardson, 1996), pudiendo incluso abarcar desde un icono natural hasta otro de menor relevancia local (Prideaux, 2009), e influyen en las decisiones del viaje (Gee et al., 1984). Algunos autores llegan incluso a afirmar que sin recursos no habría necesidad alguna de desarrollar servicios turísticos (Benckendorff, 2004; Ferrario, 1979; Fyall et al., 2001; Nickerson y Kerr, 1998; Pigram, 1983; Swarbrooke, 2002; Yale, 1997).

\section{DE LA PLANIFICACIÓN DE LOS RECURSOS: ENFOQUES PARA SU EVALUACIÓN Y MODELOS PARA SU ADAPTACIÓN AL USO TURÍSTICO}

\subsection{Enfoques para la evaluación del atractivo de los recursos}

Conscientes de la importancia de los recursos, algunas técnicas de evaluación comenzaron a aplicarse hacia finales de la década de los 50 del siglo pasado, con una orientación hacia el sector turístico en Europa y hacia los recursos recreativos en América del Norte. Para ello, se tomaron como modelos de referencia básicos tanto las técnicas de evaluación paisajística, desarrolladas por arquitectos y geógrafos; económicas, centradas en la relación directa entre el índice de visitas y la distancia a recorrer hasta el área recreativa; y unas terceras que abogaban por la valoración de quienes los utilizaban: los visitantes. Ya durante la década de los 60 aparecieron también instituciones públicas turísticas de ámbito internacional que realizaron sus aportaciones al estudio de los recursos. 
Cuadro 4. Enfoques para la evaluación de los recursos

\begin{tabular}{|c|c|c|}
\hline ENFOQUE & DESCRIPCIÓN & AUTORES DE REFERENCIA \\
\hline Analítico & $\begin{array}{l}\text { Denominador común: presencia o ausencia } \\
\text { de determinados componentes valorados } \\
\text { individualmente, pero comparados entre } \\
\text { semejantes. } \\
\text { Objetivo: tasar solo el valor intrínseco del } \\
\text { recurso }\end{array}$ & $\begin{array}{l}\text { UIOOT (1971a), Coya (1975), OMT (1977), } \\
\text { OEA (1978), WTO (1979), Smith (1987), Wu et } \\
\text { al. (1992), Yang (1994), Mantero et al. (1998), } \\
\text { Bao y Chu (1999), Garrod y Fyall (2000), } \\
\text { Priskin (2001), Deng et al. (2002), Reyes y } \\
\text { Sánchez (2005), Ávila (2008), Franco-Maass } \\
\text { et al. (2009), Cebrián y González (2010), latu } \\
\text { y Bulai (2011) }\end{array}$ \\
\hline Económico & $\begin{array}{l}\text { Denominador común: recursos sin valor de } \\
\text { mercado. } \\
\text { Objetivo: determinar económicamente los } \\
\text { posibles usos alternativos y compatibles }\end{array}$ & $\begin{array}{l}\text { Clawson (1959), Hotelling (1958), Knetsch } \\
\text { (1963), Smith (1987), Krutilla y Fischer (1975), } \\
\text { Cesario y Knetsch (1976), Var et al. (1977) }\end{array}$ \\
\hline Preferencias & $\begin{array}{l}\text { Denominador común: evaluación de las } \\
\text { preferencias de la demanda sobre los } \\
\text { recursos. } \\
\text { Objetivo: identificar el mayor valor de un } \\
\text { determinado recurso. }\end{array}$ & $\begin{array}{l}\text { Piperoglou (1967), UIOOT (1971a), Gearing } \\
\text { et al. (1974), Ritchie y Zinns (1978), Ferrario } \\
\text { (1979), Cinelli (1985) }\end{array}$ \\
\hline Mixto & $\begin{array}{l}\text { Denominador común: investigación analítica } \\
\text { que introduce las valoraciones de la } \\
\text { demanda. } \\
\text { Objetivo: eliminar parte de la subjetividad } \\
\text { condicionada a las valoraciones expertas. }\end{array}$ & $\begin{array}{l}\text { Álvarez y Leno (1986), Leno (1990), Aledo } \\
\text { y Mazón (1998), López (1998; 2001; 2005; } \\
\text { 2006; 2009; 2014) }\end{array}$ \\
\hline
\end{tabular}

Fuente: elaboración propia a partir de Camara y Morcate (2014:57)

Tras más de sesenta años de técnicas de evaluación, y en un intento por ordenar tales propuestas, Camara y Morcate (2014) y Varisco et al. (2014), siguiendo a Leno (1990), caracterizan tres enfoques básicos para la evaluación de los recursos (cuadro 4). Uno primero, de carácter analítico, que se aplica a aquellas técnicas cuyo denominador común considera la presencia o ausencia de determinados componentes que, siendo valorados individualmente a partir de la comparación entre semejantes, ofrecen una evaluación de su calidad. Se tasa solo el valor intrínseco del recurso y su aplicación, esencialmente, ha sido para evaluar áreas naturales, playas y, con algunas modificaciones posteriores, todo tipo de recursos.

Un segundo grupo, con un enfoque económico, que tiene por objeto determinar el valor de los posibles usos alternativos y compatibles en un área concreta sobre recursos que, inicialmente, no son de carácter comercial y, por lo tanto, no tienen un valor en el mercado. Un tercer grupo, cuyo enfoque se basa en la evaluación de las preferencias de la demanda sobre los recursos. Parte del supuesto de que cuanto mayor será el valor otorgado a un determinado recurso, mayor expectación despertará entre sus usuarios potenciales o reales. Finalmente, el último grupo de carácter mixto, que se da en aquellos casos en los que la investigación, normalmente de tipo analítica, introduce las valoraciones de la demanda para ponderar las variables. 
Este surtido de enfoques ha generado una multiplicidad de técnicas de evaluación de los recursos ${ }^{2}$, técnicas que han ido evolucionado con el paso de tiempo, desarrollando nuevos métodos de análisis e incorporando paulatinamente otras visiones más ambientales y de participación de agentes sociales.

\subsection{Modelos para la adaptación al uso turístico de los recursos}

Los estudios relacionados con los recursos turísticos han estado faltos de lo esencial: una definición clara y rigurosa capaz de establecer el punto de partida sobre qué es (Ávila, 2008; Leiper, 1990; Swarbrooke, 2002; Walsh-Heron y Stevens, 1990). Y, probablemente, sea esta la razón por la que existan múltiples aportaciones, pero ninguna que hayan conseguido un consenso en su concepción. Esta falta de acuerdo existente sobre qué hace que un recurso sea turístico (Leask y Fyall, 2006; Richardson, 1996; Swarbrooke, 2002; Weaver y Lawton, 2007; Weidenfeld y Leask, 2013), es debido, fundamentalmente, a la amplia variedad de perspectivas desde la cual analizarlo (desde su naturaleza intrínseca, desde la óptica del visitante, desde su modelo de gestión, desde la investigación, desde su marco normativo), de términos universalmente utilizados (atractivo, característica, sitio, lugar, espacio,...), del cambio constante y diversidad de los intereses de los visitantes (descanso, acción, prestigio, solidaridad, curiosidad,...) y de la variabilidad de recursos turísticos existentes (balnearios, parques naturales, centros urbanos, monumentos históricos, parques temáticos,...) (Lew, 1987; P. Pearce, 1991, 1998; Stevens, 1991).

Así pues, ¿qué es un recurso turístico?

Para esta investigación se toma como referencia la Teoría de la Renovación del Patrimonio Turístico (Organización Mundial del Turismo, 1979), que si bien ha sido poco reproducida en la literatura sobre turismo (Bote, 1990; Calderón, 2005; Leno, 1991), resulta adecuado prestarle atención. En ella, el concepto de recurso turístico queda asociado, además de a la existencia de atractivo, a que haya una transformación humana para su adaptación a la actividad turística.

El argumento que se sustenta tal decisión es el siguiente: puesto que la mayoría de los recursos naturales y culturales no han sido concebidos con una finalidad turística, estos deben ser adecuados a ese nuevo uso para que, en primer lugar, no se vean afectados por ella $y$, seguidamente, puedan cumplir las expectativas de quienes los visitan. Bajo esta declaración se exponen a continuación los modelos, encontrados todos ellos en la literatura académica en lengua inglesa, que asientan su base en el concepto de adaptación al uso turístico.

\subsubsection{El modelo de Gunn o The Tripartite Attraction Concept}

Clare A. Gunn, uno de los precursores de la planificación del turismo y defensor de los recursos como primer componente del sistema turístico, expone, en un trabajo teórico para el

2. La mayoría de modelos de evaluación de recursos aplican el modelo de la Organización de Estados Americanos - CICATUR, sobre todo en la planificación turística del área Iberoamericana (Navarro, 2015, Varisco et al., 2014), y siendo también un referente prioritario en la problemática de ordenación, catalogación y valoración de los recursos para el caso español (Calderón, 2005). 
desarrollo turístico regional, que el análisis de los recursos revela ciertos elementos y relaciones que cabe considerar en la creación de los atractivos (Gunn, 1972, p.55). Estos elementos a los que se refiere el arquitecto y sus relaciones son los que conforman el tripartite attraction concept, definido posteriormente por Benckendorff (2004, p.11) como el ajuste espacial del recurso, o por Weaver y Lawton $(2007$, p.109) como el marco espacial para la adaptación de los recursos.

El primero de estos elementos, el núcleo, se considera la razón de ser de lo que será el recurso turístico (figura 2). Si se piensa, por ejemplo, en una catarata el núcleo sería su sonido y la vista del agua mientras cae, si en cambio es una montaña su pico representaría ese punto central y, en el caso de un edificio histórico, aquel elemento que representa su máximo exponente de distinción (la fachada, una sala principal, el claustro, el patio de armas,...). Así que a la hora de estructurar un recurso para su conversión turística, el núcleo debe representar su fundamento, a partir de una cualidad que empareje o sobrepase la imagen retenida por los visitantes.

Figura 2. Tripartite Attraction Concept (Gunn, 1972)

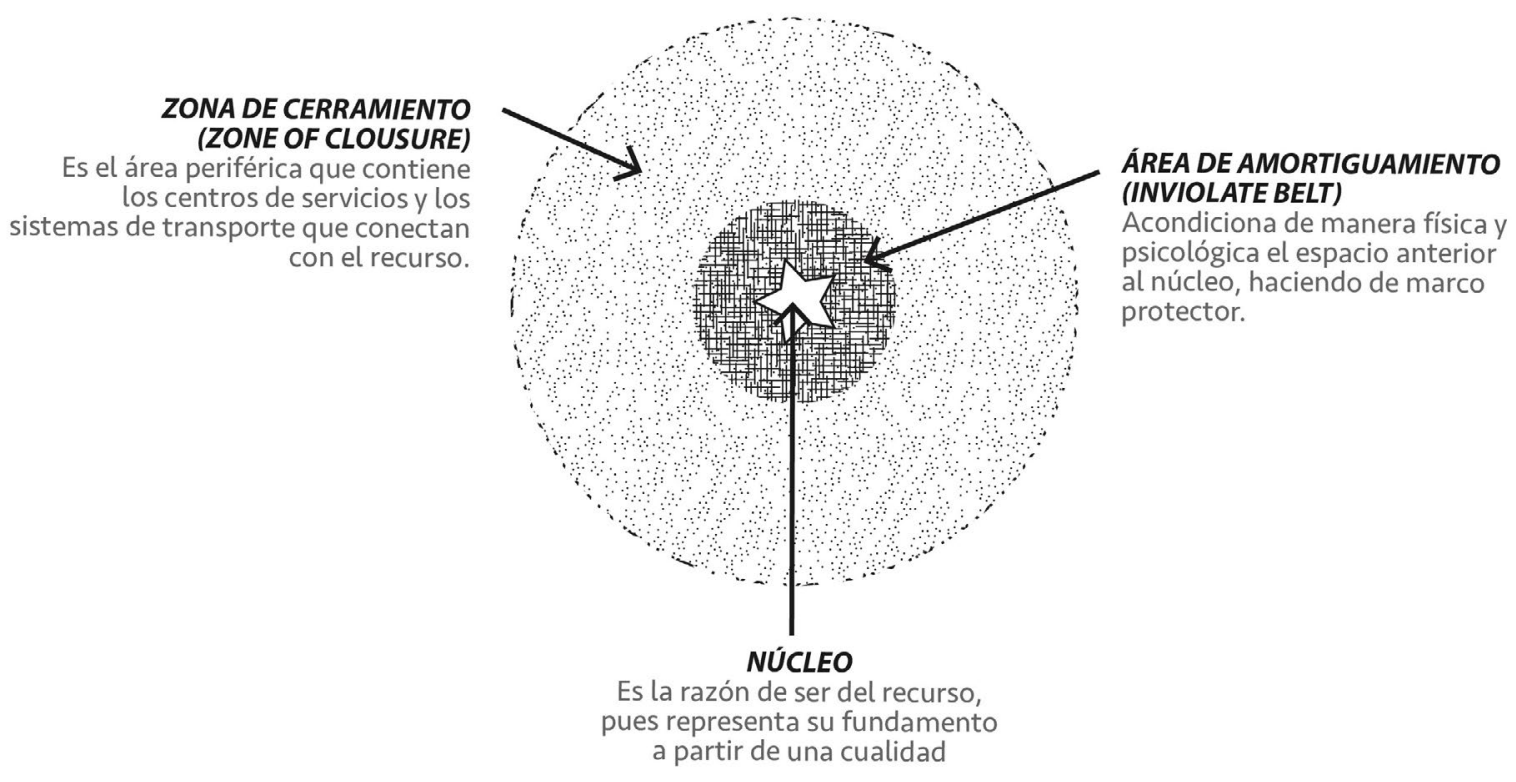

Fuente: traducción y elaboración propia a partir de Gunn (1972)

Si el núcleo es frágil o único, indica el autor, deberían extremarse sobre él las medidas en su planificación, más aun si el flujo que espera generarse es grande. En estos casos los visitantes deberían retenerse en el límite de esa característica principal para que puedan experimentarla a través de lecturas interpretativas, presentaciones, simulaciones, exhibiciones o visitas en transporte (sightseeing). El objetivo es que, independientemente del método usado, se prevenga el contacto físico que pueda dañarlo tanto a él como a su entorno.

El segundo de los elementos, el área de amortiguamiento o inviolate belt, tiene como función acondicionar de manera física y psicológica el espacio anterior al núcleo. Se presenta como el marco de esa característica principal del recurso turístico (Gunn, 1997, p.55). Esta 
área posee una función fundamental, mucho más importante de lo que en principio se le atribuye, pues, sin ella el núcleo queda completamente desprovisto de protección alguna. Su creación, expone el autor, requiere de una especial sensibilidad y creatividad, y no solo por parte de quien lo diseña, sino también por parte de los diferentes actores implicados cuyos intereses pueden dificultar su realización.

Bien es cierto que no resulta fácil incorporar esta área de amortiguamiento en el diseño de todo recurso turístico, más cuando este no nace con esa intención, sino que es adaptado para un disfrute turístico. Sin ir más lejos, un edificio histórico, cuya característica principal sea su fachada, puede verse afectado negativamente por una política urbana que no considere agresivo o lesivo rodearla de edificaciones modernas, y que cuyos fines distintos a los turísticos no han sido integrados en el entorno convenientemente. Otro ejemplo sería los espacios naturales, donde existen puntos concretos de elevado atractivo por sus cualidades paisajísticas, y que no han sido tenidos en cuenta a la hora de emplazar infraestructuras generales o explotaciones extractivas (carbón, mármol, arenas, madera...).

Finalmente, el tercer elemento, que conformaría este concepto alrededor del recurso turístico, sería la zona de cerramiento o zone of closure. Se trata del área periférica donde estarán contenidos los centros de servicios (alojamiento, restauración, comercios, alquiler de vehículos, bancos, información, etc.) y los sistemas de transporte que conectarán con él.

Este modelo parece llevar implícito que cualquier recurso que no tenga las tres zonas adecuadamente identificadas (ya sea porque el núcleo está pobremente definido, el contenido inadecuadamente interpretado o los servicios mínimamente desarrollados) quedará incompleto, por lo que su gestión será del todo compleja y su capacidad de generar críticas por parte de la demanda y de los residentes garantizada (Pearce et al., 2001, p.117).

Parece lógico pensar que este modelo será de mejor aplicación a recursos individuales en oposición a aquellos espacios que compartan múltiples núcleos (como un centro histórico, un parque natural, un barrio,...), pues, las funciones de interdependencia entre los atractivos dentro de esta zona no estarán siempre claras debido a la diversidad de actores y sus intereses (P. Pearce, 1991, p.51). Sea como fuere, la planificación de estos tres elementos, a través de un plan integral que mejore la satisfacción no solo de los visitantes, también de los residentes y del sector privado, se presenta como una meta insoslayable.

\subsubsection{El modelo de Canter o the Theory of Sense of Place}

Esta segunda aproximación a las teorías y modelos sobre los recursos turísticos se encuentra inserta en el trabajo de Canter (1977). Definida inicialmente por Tuan (1974) como aquellos lazos afectivos que se tienen con el entorno material, los investigadores en sense of place han teorizado ampliamente sobre la conexión emocional entre las personas y los lugares (Deutsch et al., 2011). Si bien esta propuesta quedaría enmarcada en el campo de la psicología del espacio, puede ser aplicada también en la comprensión de los recursos para su uso turístico (Pearce et al., 2001).

Esta teoría sustenta que existen muchos conceptos en las ciencias sociales que buscan en realidad describir aspectos de la relación entre el ser humano y su medio ambiente, 
entremezclando facetas cognitivas, afectivas y conativas (Jorgensen y Stedman, 2006). Así pues, el apego al lugar (place attachment), entendido como el vínculo positivo que se desarrolla entre una persona y su entorno; la identidad del lugar (place identity), referida la identificación de la persona con el entorno; la dependencia del lugar (place dependency), basada en la fuerza percibida de la asociación entre una persona y el lugar; y la satisfacción del lugar (place satisfaction), son construcciones que aparecen continuamente en la literatura sobre psicología ambiental y pueden encuadrarse bajo el término paraguas de sense of place (Shamai, 1991).

Figura 3. Modelo teórico de Canter (1977)

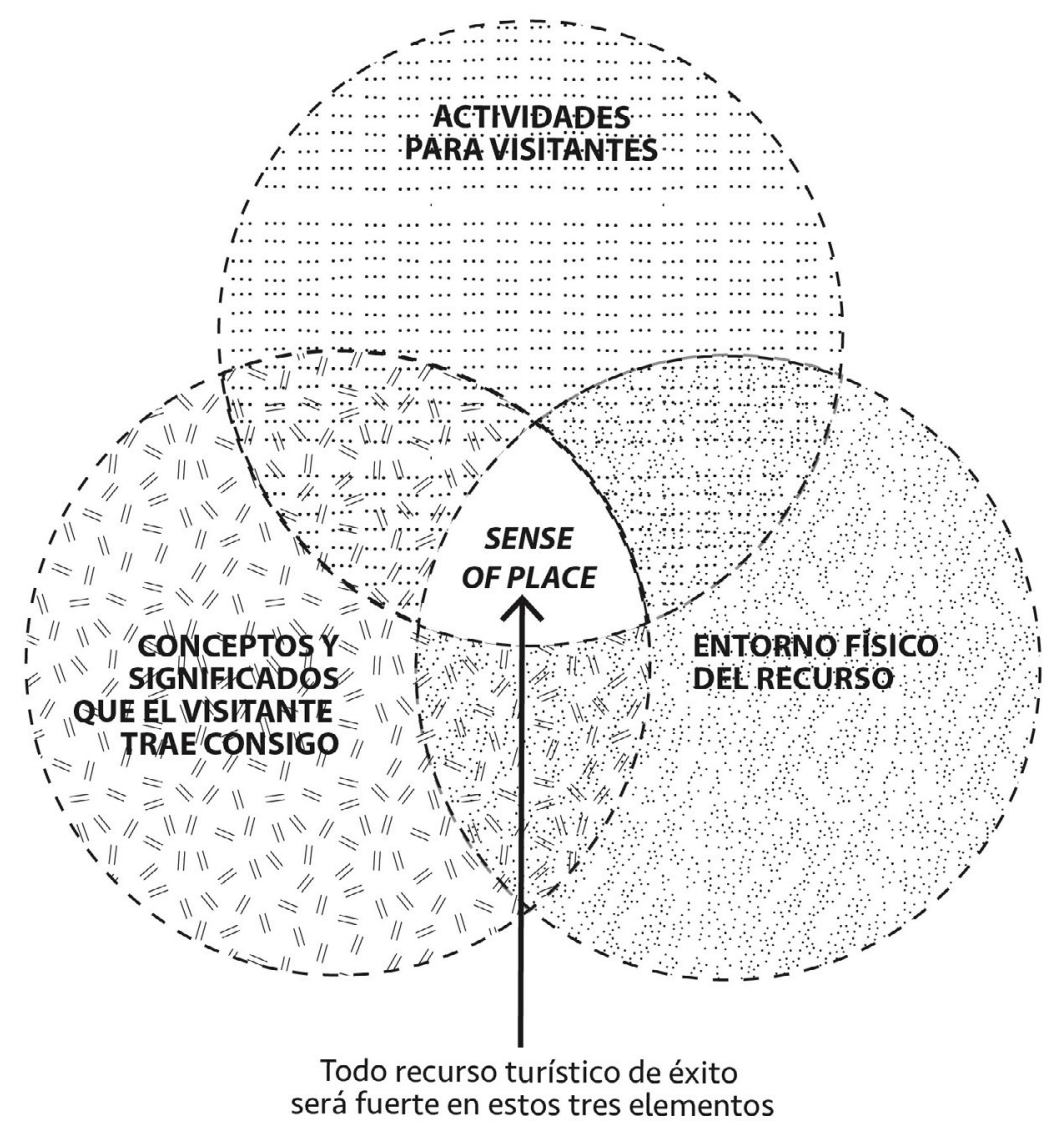

Fuente: traducción y elaboración propia a partir de Canter (1977)

Para Canter (1977) lo que un lugar es no puede ser totalmente comprendido hasta que se sabe qué comportamiento está asociado con él, cuáles son los parámetros físicos de su marco, y cuál es la descripción o concepción que la gente tiene sobre su entorno físico (Canter, 1977, pp.159 - 160). Partiendo de esta premisa, y a partir de la creación de un diagrama de Venn, el autor sintetiza los tres componentes necesarios para experimentar el genius loci ${ }^{3}$ (figura 3). Así pues, un buen recurso turístico es aquel en el que sus visitantes tienen una concepción clara sobre el lugar, comprenden las actividades que en él se desarrollan y facilita

3. Nota del autor: esta expresión latina propia de la mitología romana es utilizada para referirse al espíritu protector de un lugar. En la arquitectura moderna, Christian Norberg-Schulz utilizó esta expresión para referirse a la adaptación de los espacios públicos en el contexto donde se ubican. 
además la imaginación. Asimismo, los elementos físicos que comprende ese recurso deben ser distintivos y estéticamente agradables.

Resulta interesante este modelo en tanto en cuanto es capaz de explicar que un mismo espacio, en función del comportamiento y la conceptualización que sobre él tengan los diferentes visitantes, puede generar otros subespacios.

Un ejemplo de este modelo es presentado por Ram et al. (2016) para demostrar que aquellos recursos turísticos que ofrecen un mayor valor sobre la experiencia percibida del patrimonio sienten este como más auténtico, frente a aquellos donde la experiencia posee menor valor. Por lo tanto, resulta decisivo analizar los recursos y las conductas concretas a ellos asociados previamente, para que, en caso de ser compatible con el recurso y los potenciales targets, puedan adecuarse para que confluyan personas con motivaciones distintas sin que altere la preservación del elemento.

\subsubsection{La teoría de la atractividad de MacCannell (The Attraction Theory)}

Sobre la base inicial de la semiótica desarrollada por Charles Pierce, MacCannell (1976) argumenta que cualquier lugar es susceptible de ser transformado en recurso turístico, porque más que su significado (lo que el recurso es) importa verdaderamente lo que simboliza (lo que el recurso representa). Según este sociólogo, la sacralización de los recursos (de ahí que esta teoría sea también denominada como la Teoría de la Sacralización) es un constructo artificial que tiene como finalidad convertir un recurso en turístico, y que requiere dos pasos concatenados:

Cuadro 5. Fases para convertir un recurso en turístico (MacCannell, 1976)

\begin{tabular}{|l|l|}
\hline \multicolumn{1}{|c|}{ FASE } & \multicolumn{1}{c|}{ DESCRIPCIÓN } \\
\hline Naming (Denominación) & $\begin{array}{l}\text { Esta fase tiene lugar cuando el lugar es diferenciado de otros } \\
\text { similares por ser digno de preservación }\end{array}$ \\
\hline $\begin{array}{l}\text { Framing and elevation } \\
\text { (enmarcado y elevación) }\end{array}$ & $\begin{array}{l}\text { Tras la preservación, el objetivo de esta fase es marcar una frontera } \\
\text { sobre el lugar (framing) para protegerlo y mejorarlo, siendo } \\
\text { posteriormente exhibido (elevation) }\end{array}$ \\
\hline $\begin{array}{l}\text { Enshrinement } \\
\text { (consagración) }\end{array}$ & $\begin{array}{l}\text { En esta fase pueden generarse reglamentaciones y se erigen en el } \\
\text { lugar monumentos o indicaciones que representan el estatus especial }\end{array}$ \\
\hline $\begin{array}{l}\text { Mechanical reproduction } \\
\text { (reproducción mecánica) }\end{array}$ & $\begin{array}{l}\text { Las imágenes y modelos del lugar son reproducidos para su } \\
\text { comercialización a través de souvenirs. }\end{array}$ \\
\hline $\begin{array}{l}\text { Social reproduction } \\
\text { (reproducción social) }\end{array}$ & $\begin{array}{l}\text { Esta fase final aparece cuando su nombre se antepone para nombrar } \\
\text { territorios, empresas, grupos, instituciones,... }\end{array}$ \\
\hline
\end{tabular}

Fuente: elaboración propia a partir de MacCannell (1976, p.44)

1. La actitud ritualista de los turistas cuando genera un sentir colectivo de que ciertos sitios "deben" ser vistos.

2. La sacralización del sitio, a partir de la implementación de cinco fases (cuadro 5) 
Esta visión del recurso se separa de las concepciones previas (y las que vendrán con posterioridad), pues, en principio solo uno de los tres componentes identificados por el autor coincide con la idea de recurso turístico en sí mismo: la vista.

Jacobsen (1997) aplicó esta teoría para describir y explicar el grado de sacralización de North Cape como recurso turístico. Concluyó que las fases no se aplicaban una detrás de otra, sino que podían darse al mismo tiempo (Jacobsen, 1997, p.353), incluso podían tener un desarrollo más rápido o más lento y, además, podían retroceder para asentarse y conseguir con ello una mayor relevancia.

Asimismo, indica que, puesto que la sacralización se relaciona con la creación de una imagen asociada a símbolos, más que con sus características inherentes, los recursos turísticos podían estar caracterizados por muy pocas cualidades internas. Y en el caso que las tuviesen, servirían de poco, pues el cambio en los motivos de las sociedades haría que los iconos a ellos asociados también tuvieran que modificarse.

Este hecho supone un choque frontal frente a la concepción que en los ámbitos académicos se tiene respecto al enfoque de los desarrollos teóricos vinculados con la línea conceptual del marco OEA-CICATUR (enfoque de producto). Si hasta ahora parecía que las características intrínsecas o cualidades propias de cada recurso (singularidad o unicidad, diversidad, temporalidad, propiedad,...) eran los que definían en cierto modo (junto con los de carácter externo) la atractividad del recurso, esta visión sobre la creación de recursos turísticos reconoce abiertamente que son más bien el resultado de un proceso de construcción social (Vejsbjerg, 2013, p.3), por lo que su análisis no puede quedarse en una mera descripción estática de su importancia científica. Con esta teoría desaparece esa excesiva naturalización de los recursos que les atribuía un carácter unívoco, natural y por lo tanto no social (Bertoncello y Troncoso, 2003, p.28)

Todo parece indicar, según esta teoría, que un sitio puede convertirse en recurso turístico cuando se le otorga algún valor especial y significativo y es, además, comunicado a los visitantes a través de la interpretación y promoción (Vejsbjerg, 2013). Si ese valor se relaciona directamente con su carácter patrimonial, la positividad que le infringe supondrá una marca de distinción para los lugares en los que se encuentra, siendo esa positividad el núcleo de su atractividad más que sus cualidades intrínsecas (Almirón et al., 2006, p.115).

En años posteriores Leiper (1990), en base al trabajo de MacCannell (1976), desarrollará su propuesta de sistemas de atractivo turístico. Pero mientras Gunn (1972) y MacCannell (1976) centran el foco de atención en el núcleo, en el modelo de Leiper (1990) se deja al recurso turístico como parte del sistema, insistiendo más en la relación marcadores - motivación que en los propios rasgos de los recursos (Page y Connell, 2006). Como ya dijo Pearce (1999) en su momento: una debilidad del modelo de Leiper (1990) es la falta de atención prestada al significado de los recursos.

\section{CONCLUSIONES}

Sin entender que el turismo es una actividad compleja que superpone diferentes sectores sociales, políticos y económicos, los cuales reflejan sobre el territorio sus intereses, la 
no existencia de una planificación adecuada genera, irremediablemente, impactos inesperados e indeseados. Es lo que declara Barrado (2004) en su concepción sobre la producción/ consumo de los productos turísticos. Comprender cómo se genera este tipo de producción no es suficiente si no se consideran los impactos que se perpetran sobre el territorio, pues, estos acaban, irremediablemente, formando parte del propio producto turístico. De este modo los impactos del turismo también actúan positiva o negativamente en la percepción y en los niveles de satisfacción.

De ahí la evolución de la planificación del turismo en los últimos 50 años. Quizás, pueda interpretarse que existía una gran insatisfacción en el modo en cómo el turismo era planificado o, al menos, que existía una necesidad considerable de realizar mejoras continuas (Getz, 1986). En palabras de López (2007) esta se debe a que se diseña en función de las realidades de cada momento histórico y, por lo tanto, la planificación también ha tenido objetivos y medios distintos según dichas realidades temporales. Hall (2008) dentro de esta línea comenta que las perspectivas y acciones cambian y cambiarán con el tiempo en relación a las experiencias, conocimiento base, valores e ideologías, el contacto con diferentes stakeholders, los cambios legislativos y marcos institucionales, así como el entorno, solo por citar algunos factores. Además, tales perspectivas y acciones se substituirán de acuerdo con el mismo proceso de planificación (Hall, 2008, p.82), concluyendo que, en verdad, no existe una posición absoluta en la planificación del turismo.

Se observa, sin embargo, cierta evolución: se pasa de la toma de decisiones centralizada a otra más participativa y legitimada; la planificación inicial de carácter económico pasa a considerar otros elementos espaciales, ambientales y de mercado; la planificación descriptiva deja paso a la prospectiva; y la sostenibilidad, sin presencia alguna en los enfoques iniciales, pasa a ser la razón del objeto a planificar (Hall y Page, 2010).

Descendiendo a la planificación de los recursos, en lo que respecta a la labor de evaluar la materia prima, parece que tampoco esta sea una cuestión resuelta. Sí lo es la importancia de su valoración, a tenor de su presencia en los modelos de planificación del turismo, por ser la que justifica el desarrollo de los elementos de soporte, la creación de organismos públicos de gestión o la creación de nueva infraestructura. Pero, tal y como afirma Leno (1993) y considerando la gran diversidad de variables y posturas presentes en las evaluaciones, se hace imposible que exista una metodología aceptada de forma global (Aledo y Mazón, 1998, p.61). Y parece que la razón está en la esencia misma de la idea de recurso: es la valoración cultural que se asocia a ellos lo que los convierte en recursos.

Así pues, y como constataron Leno (1992) y Pulido et al. (2013), el concepto de recurso es algo subjetivo, relativo y funcional. La subjetividad por la dependencia que existe en su interpretación por parte de la sociedad, la relatividad por la interpretación según cada cultura, y la funcionalidad porque todo recurso debe tener un uso que responda a una necesidad. De este modo, ¿cómo determinar entonces el valor de un elemento neutro si existen tantos condicionantes subjetivos? ¿existen recursos exclusivamente turísticos o son en verdad recursos a los que se califica de turísticos porque decidimos atribuirles esa función y valor? Lo que está claro es que hablar de recursos implica hablar de necesidades humanas y, aunque aquellos pueden ser evaluados desde perspectivas distintas (desde su naturaleza intrínseca, desde las percepciones de los visitantes o desde su capacidad para generar beneficios económicos), 
resulta imprescindible identificar en ese proceso de valoración lo que el recurso aportará al interés y a la motivación del futuro visitante. Así pues, y como primer paso, resulta vital identificar el núcleo o núcleos de todo recurso. Este debería ser, sin ninguna duda, el objeto de toda evaluación. Y para ello resulta imprescindible conocer, por un lado, los intereses y motivaciones del visitante que se desea atraer y, por otro, si tales intereses son compatibles con la conservación del recurso y con la percepción que sobre él tenga asociada la población local.

Y llegados a este punto, asumir, igualmente, que la sola valoración del recurso no es suficiente para ponerlo a disposición de la mirada turística y, por ende, hablar de recurso turístico. Es necesario acometer la otra cara de la planificación de los recursos: su adecuada adaptación a ese nuevo fin, pues, lógicamente, la gran mayoría de ellos no fueron creados con esa intención de ocio. Ahora bien, acomodar no debe significar estandarizar ni musealizar. Acomodar supone pensar en un visitante concreto, un visitante interesado e interesante, al que dirigir una oferta de actividades acordes siempre a la idiosincrasia del recurso y del medio social en el que se encuentra inserto.

Evaluar y adaptar se presentan, pues, como las dos caras de una misma moneda: la planificación de los recursos al uso turístico. Sin embargo, llama la atención la gran diversidad de trabajos encontrados sobre cómo evaluar la materia prima (encuadrados en diferentes enfoques), frente a las pocas propuestas metodológicas existentes acerca de cómo un recurso debe adaptarse a su uso turístico.

Es prioritario, cuando no urgente, avanzar hacia la unión entre evaluar y adaptar cuando se hable de la materia prima de la actividad turística, y para ello resulta imprescindible consolidar nuevas metodologías que integren ambos pilares.

\section{REFERENCIAS BIBLIOGRÁFICAS}

Acerenza, M. (1984). Administración del turismo: Conceptualización y organización. México: Trillas.

Aledo, A., y Mazón, T. (1998). Análisis y metodología para el estudio del sector turístico de una comarca: El caso del Bajo Segura (Alicante). Estudios Turísticos, (137), 55-66.

Almeida, F., Balbuena, A., y Cortés, R. (2015). Resident's attitudes towards the impacts of tourism. Tourism Management Perspectives, 13(7), 33-40.

Almirón, A., Bertoncello, R., y Troncoso, C. (2006). Turismo, patrimonio y territorio. una discusión de sus relaciones a partir de casos de Argentina. Estudios y Perspectivas en Turismo, 15(2), 101-120.

Álvarez Cuervo, R., y Leno Cerro, F. (1986). Estudio para la valoración económica y situación estructural del mercado turístico riojano. Novotecni.

Andereck, K. L., y Vogt, C. A. (2000). The relationship between residents' attitudes toward tourism and tourism development options. Journal of Travel Research, 39(1), 27-36.

Andriotis, K. (2000). Local community perceptions of tourism as a develoment tool: The is/and of Crete. (Unpublished Bournemouth University, Bournemouth (UK).

Anton, S., y González, F. (2005). Planificación territorial del turismo. Barcelona: Editorial UOC. 
Aramberri, J. R. (1986). (1986). Turismo y sociedad. Problemas en la planificación social del turismo. Seminario de Planificación Turística. Universidad Internacional Menéndez Pelayo, Sevilla.

Arrillaga, J. I. d. (1962). Ensayos sobre turismo. Barcelona: Editur.

Ávila, R. (2008). Metodología básica para la evaluación ponderada de los recursos patrimoniales en su proceso hacia la conversión en productos turísticos. En Universidad de Sevilla, Turismo rural y desarrollo local, (pp. 229-238), Secretariado de Publicaciones (Ed.)

Bao, J., \& Chu, Y. (1999). Tourism geography. Beijing: Higher Education Press.

Barrado, D. (2004). El concepto de destino turístico. una aproximación geográfico - territorial. Revista de Estudios Turísticos, 160, 45 - 68.

Barrado, D. (2011). Recursos territoriales y procesos geográficos: el ejemplo de los recursos turísticos. Estudios Geográficos, LXXII (270), 35-58. doi: 10.3938/estgeogr.201102

Barrado, D., y Ávila, R. (2010). El tratamiento del espacio y de la actividad turística. En Galiana Martín, L. y Vinuesa Angulo, J (Ed.), Teoría y práctica para una ordenación racional del territorio. Madrid: Síntesis.

Benckendorff, P. (2004). Planning for the future: A profile of australian tourist attractions. PhD. Thesis.

Bertoncello, R., y Troncoso, C. (2003). El lugar y las redes. Turismo en Quebrada de Humahuaca (Argentina). Huellas, 8(11), 38.

Bote Gómez, V. (1990). Planificación económica del turismo: de una estrategia masiva a una artesanal. México: Trillas.

Boullón, R. (1978). El sistema turístico. México: Trillas.

Boullón, R. (2006). Planificación del espacio turístico. México: Trillas.

Bowman, I. (1934). Geography in relation to the Social Sciences. Scriben.

Burns, P. (1999). Paradoxes in planning tourism elitism or brutalism? Annals of Tourism Research, 26(2), 329-348. http://dx.doi.org/10.1016/S0160-7383(98)00099-1

Burns, P. (2004). Tourism planning: A third way? Annals of Tourism Research, 31(1), 24-43.

Calderón, F. (2005). Distrito turístico rural un modelo teórico desde la perspectiva de la oferta. Especial referencia la caso andaluz. Universidad de Málaga.

Callizo, J., y Lacosta, A. (1999). Un estudio tipológico de los recursos turísticos. En J. Tudela (Ed.), Régimen jurídico de los recursos turísticos. (pp. 19-76). Zaragoza: Diputación General de Aragón, Departamento de Presidencia y Relaciones Institucionales.

Camara, C., y Morcate, F. (2014). Metodología para la identificación, clasificación y evaluación de los recursos territoriales turísticos del centro de ciudad de Fort-de-France. Arquitectura y Urbanismo, 35(1), 48-67.

Canter, D. (1977). The psychology of place. London. Architectural Press.

Cebrián Abellán, F., y García González, J. A. (2010). Propuesta metodológica para la identificación, clasificación y puesta en valor de los recursos territoriales del turismo interior. La provincia de Albacete. Boletín de la Asociación de Geógrafos Españoles, 54, 361.

Cesario, F., y Knetsch, J. (1976). A recreation site demand and benefit estimation model. Regional Studies, 10, 97-104.

Cinelli, A. (1985). Il potenziale turistico. En G. Corna Pellegrini, \& A. Frigerio (Eds.), Turismo come e perché: Modello di ricerca geografica e psicologica: Il territorio varesino (pp. 201-274). Varese; Milano: ASK edizioni; Unicopli. 
Clawson, M. (1959). Method of measuring the demand for and value of outdoor recreation. Washington: Resources for the future.

Conti, A., y Cravero, S. (2010). Patrimonio, comunidad local y turismo: La necesidad de planificación para el desarrollo sostenible. Notas en Turismo y Economía, 1, 8-31.

Cooper, C., Fletcher, J., Fyall, A., Gilbert, D., \& Wanhill, S. (2007). El turismo: Teoría y práctica. Madrid: Editorial Síntesis.

Coya Sanz, M. (1975). Un análisis de la distribución espacial de la demanda. Estudios Turísticos, $47-48,139$.

de Grandpre, F. (2007). Attraits, attractions et produits touristiques: Trois concepts distincts dans le contexte d'un developpement touristique regional. Téoros, 26(2), 12-18.

Deng, J., King, B., y Bauer, T. (2002). La evaluación de atractivos naturales para el turismo. Annals of Tourism Research En Español, 4(1), 144.

Deutsch, S., Yoon, S., y Goulias, K. (2011). Unpacking the theory of sense of place, is it useful to choice modeling? International Choice Modeling Conference 2011, Leeds (United Kingdom).

Doswell, R. (1997). Tourism: How effective management makes the difference. Oxford; Boston: Butterworth-Heinemann.

Dredge, D. (1999). Destination place planning and design. Annals of Tourism Research, 26(4), $772-791$.

Ferrario, F. F. (1979). The evaluation of tourist resources: An applied methodology. Journal of Travel Research, Vol 3, 18-22.

Franco-Maass, S., Osorio-Garcia, M., Nava-Bernal, G., y Regil-García, H. H. (2009). Evaluación multicriterio de los recursos turísticos. Estudios y Perspectivas en Turismo, 18, 208.

Fyall, A., Leask, A., y Garrod, B. (2001). Scottish visitor attractions: A collaborative future? International Journal of Tourism Research 3, 211-228.

Garrod, B., y Fyall, A. (2000). Managing heritage tourism. Annals of Tourism Research, 27(3), 682-708. http://dx.doi.org/10.1016/S0160-7383(99)00094-8

Gearing, C., Swart, W., \& Var, T. (1974). Establishing a mesure of touristic attractiveness. Journal of Travel Research, 12, 1-8.

Gee, C., Choy, D., \& Makens, J. (1984). The travel industry. Westport, CT: AVI Pub. Co.

Getz, D. (1986). Models in tourism planning: Towards integration of theory and practice. Tourism Management, 7(1), 21-32. http://dx.doi.org/10.1016/0261-5177(86)90054-3

Getz, D. (1987). Tourism planning and research: Traditions, models and futures. The Australian Travel Research Workshop ed., Bunbury, Western Australia.

Goeldner, C. R., y Ritchie, J. R. (2006). Tourism principles, practices, philosophies (10th ed.). New York: Wiley.

Godfrey, K., \& Clarke, J. (2000). The tourism development handbook: A practical approach to planning and marketing. London: Cassell.

Gulick, L. (1937). Notes on the theory of organization. New York, Columbia University. Institute of Public Administration.

Gunn, C. (1972). Vacationscape: Designing tourist regions. Austin, Texas: Bureau of Business Research, University of Texas.

Gunn, C. (1979). Tourism planning. New York: Crane Russak. 
Gunn, C. (1994). Tourism planning: Basics, concepts, cases (3rd ed.). Washington etc.: Taylor \& Francis.

Gunn, C. (1997). Vacationscape: Developing tourist areas (3rd Ed.) Tailor \& Francis.

Hall, C. M. (2000). Tourism planning: Policies, processes and relationships. Harlow, England; New York: Prentice Hall.

Hall, C. M. (2008). Tourism planning: Policies, processes and relationships (2nd ed.) Pearson Education UK.

Hall, C. M., y Lew, A. (1998). Sustainable tourism: A geographical perspective. Harlow, Essex, Eng.: Longman.

Hall, C. M., y Page, S. (2010). The contribution of Neil Leiper to tourism studies. Current Issues in Tourism, 13(4), 299-309.

Hernández Díaz, E. A. (1982). Planificación turística: Un enfoque metodológico. México: Editorial Trillas.

Herrera, B., Acle, R., y Paredes, R. (2012). Evaluación de recursos para el aprovechamiento del turismo de naturaleza en el área natural protegida estatal "Sierra de Tentzo", México. Revista de Investigación, Desarrollo e Innovación, 3(1), 8-17.

Hotelling, H. (1958). The general welfare in relation to problems of taxation and of railway and utility rates. Econometrica, 6, 242-269.

Hu, W., y Wall, G. (2005). Environmental management, environmental image and the competitive tourist attraction. Journal of Sustainable Tourism, 13(6), 617-635. http://dx.doi. org/10.1080/09669580508668584

Huete, R., y Mantecón, A. (2018). El auge de la turismofobia ¿hipótesis de investigación o ruido ideológico? Pasos. Revista de Turismo y Patrimonio Cultural, 16(1), 9-19. https://doi. org/10.25145/j.pasos.2018.16.001

latu, C., y Bulai, M. (2011). New approach in evaluating tourism attractiveness in the region of Moldavia (Romania). International Journal of Energy and Environment, 5(2), 165.

Inskeep, E. (1991). Tourism planning: an integrated and sustainable development approach. New York: Van Nostrand Reinhold.

Ivars, J. (2003). Planificación turística de los espacios regionales en España. Madrid: Editorial Síntesis.

Jacobsen, J. (1997). The making of an attraction: The case of North Cape. Annals of Tourism Research, 24(2), 341-356. 10.1016/S0160-7383(97)80005-9

Jorgensen, B., y Stedman, R. (2006). A comparative analysis of predictors of sense of place dimensions: Attachment to, dependence on, and identification with lakeshore properties. Journal of Environmental Management, 79(3), 316-327. http://dx.doi.org/10.1016/i. jenvman.2005.08.003

Kaiser, C., \& Helber, L. (1983) Turismo: planeación y desarrollo. Ediciones Diana. México.

Knetsch, J. (1963). Outdoor recreation demands and benefits. Land Economics, 39(4), 57-81.

Krutilla, J., \& Fisher, A. (1975). The economics of natural environments: Studies in the valuation of commodity and amenity resources. Baltimore: Published for Resources for the Future, Inc. by the Johns Hopkins University Press.

Lawson, F., y Baud-Bovy, M. (1977). Tourism and recreation development. London; Boston: The Architectural Press; CBI Pub. Co. 
Lawson, F., \& Baud-Bovy, M. (1998). Tourism and recreation. Handbook of planning and design. Oxford; Boston: Architectural Press.

Leask, A., y Fyall, A. (2006). Managing world heritage sites. Oxford; Burlington, Mass.: Butterworth-Heinemann.

Leiper, N. (1990). Tourist attraction systems. Annals of Tourism Research, 17(3), 367-384. 10.1016/0160-7383(90)90004-B

Leno Cerro, F. (1990). La evaluación de los recursos turísticos, el caso del Canal de Castilla. Madrid: Editorial de la Universidad Complutense de Madrid, Servicio de Reprografía.

Leno Cerro, F. (1991). Los recursos turísticos en un proceso de planificación: Inventario y evaluación.7, 7- 21.

Leno Cerro, F. (1992). La evaluación del potencial turístico en un proceso de planificación: El Canal de Castilla. Estudios Turísticos, 116, 49.

Leno Cerro, F. (1993). Técnicas de evaluación del potencial turístico. Madrid: Ministerio de Industria, Comercio y Turismo, Dirección General de Política Turística.

Lew, A. (1987). A framework of tourist attraction research. Annals of Tourism Research, 14(4), 553-575. 10.1016/0160-7383(87)90071-5

Lickorish, L. J., y Bodlender, J. (1991). Developing tourism destinations: Policies and perspectives. Harlow, Essex: Longman.

López Olivares, D. (1998). La ordenación y planificación integrada de los recursos territoriales turísticos: estudio práctico de un espacio de "desarrollo turístico incipiente". El Alto Palancia (Castellón). Castellón de la Plana. Publicacions de la Universitat Jaume I.

López Olivares, D. (2001). La evaluación de los recursos territoriales turísticos de las comarcas del interior castellonense (Comunidad Valenciana). Investigaciones Geográficas, 25, 137-157.

López Olivares, D. (2005). El sistema turístico en Nicaragua: Desarrollo turístico integrado para la región del norte, departamentos de Estelí y Nueva Segovia. Castelló de la Plana: Universitat Jaume I.

López Olivares, D. (2006). El modelo turístico de carácter sistémico e integrado como facilitador del desarrollo en los países centroamericanos: El caso de Nicaragua (Estrelí-Nueva Segovia). Documents D’Anàlisi Geogràfica, 47, 69-91.

López Olivares, D. (2014). Los recursos turísticos: Evaluación, ordenación y planificación turística: Estudio de casos. Valencia: Tirant Humanidades.

López Olivares, D., Ferreres Bonfill, J. B., y Abdelouahab Reddam, O. (2009). Estudio comparado de la potencialidad de los recursos turísticos en los parques naturales de la Sierra de Espadán (España) y Talassemtane (Marruecos). Cuadernos de Turismo, $24,91$.

López Palomeque, F. (2007). Planificación territorial del turismo y sostenibilidad: Fundamentos, realidades y retos. Turismo Y Sociedad, 8, 51.

Lundberg, D. E. (1985). The tourist business. New York, N.Y.: Van Nostrand Reinhold.

MacCannell, D. (1976). The tourist: A new theory of the leisure class. New York: Schocken Books.

Mantecón, A. (2016). La opinión pública sobre el turismo. Crítica y propuesta para una nueva orientación. Estudios y Perspectivas en Turismo, 25(2), 110-123.

Mantero, J. C., Dosso, R., y Varisco, C. (1998). Evaluación de los recursos turísticos. Aportes Y Transferencias, 2(1), 73. 
Martner, G. (1976). Planificación y presupuesto por programas (7ạ ed.). México: Siglo Veintiuno Editores.

Mason, P. (2003). Tourism impacts, planning and management (Butterworth Heinemann ed.). Amsterdam (Boston).

Middleton, V. (2001). Marketing in travel and tourism (3rd ed.). Oxford: Butterworth-Heinemann. Mill, R., \& Morrison, A. (1985). The tourism system: An introductory text (1st edition). Englewood Cliffs, Prentice-Hall.

Mill, R., \& Morrison, A. (2009). The tourism system: An introductory text (6th edition). Dubuque: Kendall/Hunt.

Miralbell et al. (2010). Gestión pública del turismo. Barcelona: UOC.

Mitchell, W. C. (1941). Conservation, liberty and economics. En National Wildlife Federation (Ed.), The foundations of conservation education. New York.

Molina, S. (1986). Planificación del turismo. México: Nuevo Tiempo Libre.

Molina, S., y Rodríguez, S. (2005). Planificación integral del turismo: Un enfoque para latinoamérica (2a Edición ed.). México: Trillas.

Muñoz Amato, P. (1963). Introducción a la administración pública: Teoría general, planificación y presupuestos. México: Fondo de Cultura Económica.

Murphy, P. (1985). Tourism: A community approach. New York: Methuen.

Nakayama, L. (1993). Relevamiento turístico. Santa Fe, Argentina: Instituto Superior de Turismo Sol;.

Navarro, D. (2015). Recursos turísticos y atractivos turísticos: Conceptualización, clasificación y valoración. Cuadernos de Turismo, 35(335), 357. doi: 10.6018/turismo.35.221641

Nickerson, N. P., y Kerr, P. (1998). Snapshots: An introduction to tourism. Scarborough, Ont.: Prentice Hall Canada.

Organización de los Estados Americanos. (1978) Estrategia de desarrollo turístico, Ecuador: Estudio de viabilidad de un polo de desarrollo turístico. Programa de Desarrollo Turístico, Sistema CICATUR-OEA, Reference OEA G155.A2.E4, 212.

Organización Mundial del Turismo. (1977). Planificación integrada del turismo. Madrid.

Organización Mundial del Turismo. (1979). Evaluación de los recursos turísticos (versión española) Madrid.

Organización Mundial del Turismo. (1994). National and regional tourims planning: Methodologies and case studies. London: Routledge.

Organización Mundial del Turismo. (1999). Agenda para planificadores locales: Turismo sostenible y gestión municipal: Edición para América Latina y El Caribe. Madrid.

Osorio García, M. (2006). La planificación turística. Enfoques y modelos. Quivera, 8 (1), 291 $-314$.

Otero, A. (2000) Planificación y manejo de atractivos turísticos culturales. VI Seminario Internacional de Arquietectura Paisajística. La Plata (Buenos Aires).

Page, S., y Connell, J. (2006). Tourism: a modern synthesis (2nd ed). London: Thomson Learning. Pearce, D. (1988). Desarrollo turístico: Su planificación y ubicación geográficas. México: Trillas. Pearce, D. (1989). Tourist development (2nd ed.) Harlow: Longman Scientif. \& Techn.

Pearce, D. (1999). Tourism in Paris studies at the microscale. Annals of Tourism Research, 26(1), 77-97.

Pearce, P. (1991). Analyzing tourist attractions. Journal of Tourism Studies, Vol. 1(№ 1), 46-55. 
Pearce, P. (1998). Marketing and management trends in tourist attractions. Asia Pacific Journal of Tourism Research, 3(1), 1-8. http://dx.doi.org/10.1080/10941669908722002

Pearce, P., Benckendorff, P., y Johnstone, S. (2001). Tourist attractions: Evolution, analysis and prospects. En E. Laws, G. Moscardo \& H. W. Faulkner (Eds.), Tourism in the twenty-first century: Reflections on experience (pp. 110-129). London: Continuum.

Phillips, P., y Moutinho, L. (2014). Critical review of strategic planning research in hospitality and tourism. Annals of Tourism Research, 48(0), 96-120. http://dx.doi.org/10.1016/j. annals.2014.05.013

Pigram, J. (1983). Outdoor recreation and resource management. New York: Croom Helm.

Piperoglou, J. (1967). Identification and definition of regions in greek tourist planning. PIRS Papers in Regional Science, 18(1), 169-176.

Prideaux, B. (2009). Resort destinations. Amsterdam; Boston: Butterworth-Heinemann/ Elsevier.

Priskin, J. (2001). Assessment of natural resources for nature-based tourism: The case of central coast region of Western Australia. Tourism Management, 22, 637.

Pulido, J., Calle, M. d. I., y Velasco, M. (2013). Turismo cultural. Madrid: Editorial Síntesis.

Ram, Y., Björk, P., y Weidenfeld, A. (2016). Authenticity and place attachment of major visitor attractions. Tourism Management, 52, 110-122. http://dx.doi.org/10.1016/i. tourman.2015.06.010

Razquin, M. (2002). Planificación turística y planificación territorial: La necesidad de una convergencia. En Blanquer, D. (Dir.) Ordenación y gestión del territorio turístico. Tirant Lo Blanch.,, 109-147.

Reid, D. G., Mair, H., y George, W. (2004). Community tourism planning: A self-assessment instrument. Annals of Tourism Research, 31(3), 623-639. http://dx.doi.org/10.1016/j. annals.2004.01.007

Reyes Pérez, O., y Sánchez Crispín, A. (2005). Metodología para determinar el potencial de los recursos turísticos naturales en el estado de Oaxaca, México. Cuadernos de Turismo, 16, 153.

Ricaurte, C. (2009). Manual para el diagnóstico turístico local: Guía para planificadores, Escuela Superior Politécnica del Litoral (Ed.).

Richardson, J. (1996). Marketing australian travel \& tourism: Principles and practice. Elsterwick, Victoria: Hospitality Press.

Ritchie, J., y Zins, M. (1978). Culture as determinant of the attractiveness of a tourism region. Annals of Tourism Research, 5(2), 252-267. 10.1016/0160-7383(78)90223-2

Sancho, A., y Buhalis, D. (1998). Introducción al turismo. Madrid: Organización Mundial del Turismo.

Sessa, A. (1975). Une nouvelle approche théorique au marché touristique. Tourism Review $30(2), 42-49$

Shamai, S. (1991). Sense of place: An empirical measurement. Geoforum,, 347-358.

Simancas, M. (Coord.)(2016) La planificación y gestión territorial del turismo. Editorial Síntesis. 327 págs.

Smith, S. L. J. (1987). Regional analysis of tourism resources. Annals of Tourism Research, 14(2), 254-273. 10.1016/0160-7383(87)90088-0 
Solsona, J. (1999). El turismo rural en la comunidad valenciana. Análisis y planificación: aplicación al Alto Mijares. Castellón de la Plana. Sociedad Castellonense de Cultura.

Stevens, T. (1991). Visitor attractions: Their management and contribution to tourism. En C. P. Cooper (Ed.), Progress in tourism, recreation and hospitality management, (pp. $106-$ 113), vol. 3. London: Belhaven.

Stylidis, D., Brian, A., Sit, J., y Szivas, E. (2014). Residents' support for tourism development: The role of residents' place image and perceived tourism impacts. Tourism Management, 45(0), 260-274. http://dx.doi.org/10.1016/i.tourman.2014.05.006

Swarbrooke, J. (2002). The development and management of visitor attractions (2nd ed.). Oxford: Butterworth-Heinemann.

Tuan, Y. (1974). Topophilia: A study of environmental perception, attitudes, and values. Englewood Cliffs, N.J.: Prentice-Hall.

Unión Internacional de Organismos Oficiales de Turismo. (1971a). Estudio sobre la oferta potencial internacional de los recursos turísticos. Genève.

Unión Internacional de Organismos Oficiales de Turismo. (1971b). La planificación turística.

United Nations World Tourism Organization. (2005). Making tourism more sustainable: A guide for policymakers. Paris; Madrid: United Nations Environment Programme, Division of Technology, Industry and Economics.

Valenzuela, M. (1986). Turismo y territorio. ideas para una revisión crítica y constructiva de las prácticas espaciales del turismo. Estudios Turísticos, 90, 47-56.

Valls, J. F. (1996). Las claves del mercado turístico: Cómo competir en el nuevo entorno. Bilbao: Deusto.

Var, T., Beck, R. A. D., y Loftus, P. (1977). Determination of touristic attractiveness of the touristic areas in British Columbia. Journal of Travel Research, January, 15, 23.

Varisco, C., Castellucci, D., González, M., Muñoz, M., Padilla, N., Campolite, L., y Benseny, G. (2014). El relevamiento turístico: Del CICATUR a la planificación participativa. Neuquén: VI Congreso Latinoamericano de Investigación Turística.

Vejsbjerg, L. (2013). La importancia científica en la selección de atractivos turísticos patrimoniales. una visión desde la espacialidad social. Scripta Nova. Revista Electrónica de Geografía y Ciencias Sociales, 17 (433)

Vera, J., López, F., Marchena, M., Anton, S. (1997) Análisis territorial del turismo: una nueva geografía del turismo. Barcelona. Ariel.

Vera, J. F. (Coord.) (2011). Análisis territorial del turismo y planificación de destinos turísticos. Valencia: Tirant lo Blanch.

Viñals, M. J., Morant, M., Quintana, R. (2011). Análisis de los criterios para la valoración turística del patrimonio natural. Investigaciones Turísticas, 1, 37 - 50.

Walsh-Heron, J., y Stevens, T. (1990) The management of visitor attractions and events. Englewood Cliffs, (New Jersey): London Prentice Hall; Prentice Hall International.

Wang, S., y Xu, H. (2015). Influence of place-based senses of distinctiveness, continuity, self-esteem and self-efficacy on residents' attitudes toward tourism. Tourism Management, 47(0), 241-250. http://dx.doi.org/10.1016/i.tourman.2014.10.007

Waterston, A. (1965). Development planning; lessons of experience. Baltimore: Johns Hopkins Press. 
Watson, S., y MacCracken, M. (2002). No attraction in strategic thinking: Perceptions on current and future skills needs for visitor attraction managers. International Journal of Tourism Research, 4, $367-378$.

Weaver, D., y Lawton, L. (2007). 'Just because it's gone doesn't mean it isn't there anymore': Planning for attraction residuality. Tourism Management, 28(1), 108-117.

Weidenfeld, A., y Leask, A. (2013). Exploring the relationship between visitor attractions and events: Definitions and management factors. Current Issues in Tourism, 16(6)

Wu, C., Li, S., y Deng, J. (1992). Landscape evaluation of ZhangJiaJie national forest park. En C. Wu, \& Z. Wu (Eds.), Studies on ZhangJiaJie national forest park (pp. 1-12). Beijin: Chinese Forestry Press.

Yale, P. (2004). From tourist attractions to heritage tourism (3a ed). Huntingdon, England.

Yale, P. (1997). From tourist attractions to heritage tourism. Huntingdon, England.

Yang, G. (1994). Tourism resources. Yunming: Yunnan University Press.

Zamorano, F. (2002) Turismo alternativo: servicios turísticos diferenciados. Animación, turismo de aventura, turismo cultural, ecoturismo, turismo recreativo. Trillas. México.

Zimmermann, E. W., y Robles, G. (1957). Recursos e industrias del mundo (1a ed. en esp). México. Fondo de Cultura Económica. 